\title{
THEORY OF UHF AND MICROWAVE MEASUREMENTS USING THE POWER EQUATION CONCEPT
}

U.S.
:PARTMENT OF COMMERCE

National D....n..1

QC

100

.05753 no.637 1973 c. 2 
The National Bureau of Standards ${ }^{1}$ was established by an act of Congress March 3, 1901. The Bureau's overall goal is to strengthen and advance the Nation's science and technology and facilitate their effective application for public benefit. To this end, the Bureau conducts research and provides: (1) a basis for the Nation's physical measurement system, (2) scientific and technological services for industry and government, (3) a technical basis for equity in trade, and (4) technical services to promote public safety. The Bureau consists of the Institute for Basic Standards, the Institute for Materials Research, the Institute for Applied Technology, the Center for Computer Sciences and Technology, and the Office for Information Programs.

THE INSTITUTE FOR BASIC STANDARDS provides the central basis within the United States of a complete and consistent system of physical measurement; coordinates that system with measurement systems of other nations; and furnishes essential services leading to accurate and uniform physical measurements throughout the Nation's scientific community, industry, and commerce. The Institute consists of a Center for Radiation Research, an Office of Measurement Services and the following divisions:

Applied Mathematics — Electricity - Mechanics - Heat — Optical Physics — Linac Radiation ${ }^{2}$ - Nuclear Radiation " - Applied Radiation ${ }^{2}$ - Quantum Electronics" - Electromagnetics" - Time and Frequency" - Laboratory Astrophysics " - Cryogenics ${ }^{3}$.

THE INSTITUTE FOR MATERIALS RESEARCH conducts materials research leading to improved methods of measurement, standards, and data on the properties of well-characterized materials needed by industry, commerce, educational institutions, and Government; provides advisory and research services to other Government agencies; and develops, produces, and distributes standard reference materials. The Institute consists of the Office of Standard Reference Materials and the following divisions:

Analytical Chemistry-Polymers-Metallurgy-Inorganic Materials-Reactor Radiation-Physical Chemistry.

THE INSTITUTE FOR APPLIED TECHNOLOGY provides technical services to promote the use of available technology and to facilitate technological innovation in industry and Government; cooperates with public and private organizations leading to the development of technological standards (including mandatory safety standards), codes and methods of test; and provides technical advice and services to Government agencies upon request. The Institute also monitors NBS engineering standards activities and provides liaison between NBS and national and international engineering standards bodies. The Institute consists of a Center for Building Technology and the following divisions and offices:

Engineering and Product Standards-Weights and Measures-Invention and Innovation-Product Evaluation Technology-Electronic Technology-Technical Analysis-Measurement Engineering-Building Standards and Code Services $^{4}$-Housing Technology ${ }^{4}$-Federal Building Technology ${ }^{4}$-Structures, Materials and Life Safety ${ }^{4}$-Building Environment ${ }^{4}$-Technical Evaluation and Application - Fire Technology.

THE INSTITUTE FOR COMPUTER SCIENCES AND TECHNOLOGY conducts research and provides technical services designed to aid Government agencies in improving cost effectiveness in the conduct of their programs through the selection, acquisition, and effective utilization of automatic data processing equipment; and serves as the principal focus within the executive branch for the development of Federal standards for automatic data processing equipment, techniques, and computer languages. The Center consists of the following offices and divisions:

Information Processing Standards-Computer Information-Computer Services -Systems Development-Information Processing Technology.

THE OFFICE FOR INFORMATION PROGRAMS promotes optimum dissemination and accessibility of scientific information generated within NBS and other agencies of the Federal Government; promotes the development of the National Standard Reference Data System and a system of information analysis centers dealing with the broader aspects of the National Measurement System; provides appropriate services to ensure that the NBS staff has optimum accessibility to the scientific information of the world, and directs the public information activities of the Bureau. The Office consists of the following organizational units:

Office of Standard Reference Data-Office of Technical Information and Publications-Library-Office of International Relations.

\footnotetext{
2 Headquarters and Laboratories at Gaithersburg, Maryland, unless otherwise noted; mailing address Washington, D.C. 20234.

2 Part of the Center for Radiation Research.

3 Located at Boulder, Colorado 80302.

- Part of the Center for Building T'echnolog.
} 
Glenn F. Engen

Electromagnetics Division Institute for Basic Standards National Bureau of Standards Boulder, Colorado 80302

NBS Technical notes are designed to supplement the Bureau's regular publications program. They provide a means for making available scientific data that are of transient or limited interest. Technical Notes may be listed or referred to in the open literat ure.

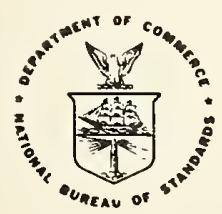

U.S. DEPARTMENT OF COMMERCE, Frederick B. Dent, Secretary NATIONAL BUREAU OF STANDARDS, Richard W. Roberts, Director Issued April 1973 


\section{National Bureau of Standards Technical Note 637}

Nat. Bur. Stand. (U.S.), Tech. Note 637, 68 pages (April 1973)

CODEN: NBTNAE

For sale by the Superintendent of Documents, U.S. Government Printing Office, Washington, D. C. 20402

(Order by SD Catalog No. C13.46:637) 
$\underline{\text { Page }}$

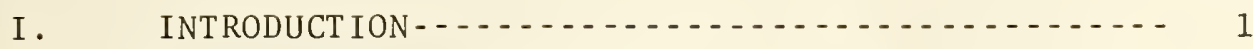

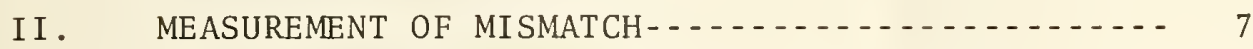

II I TWO-PORT MEASUREMENTS - . . . . . . $\ldots$

IV. MEASUREMENT OF $\mathrm{P}_{\mathrm{g}} \ldots \ldots \ldots$

V. IMPLEMENTATION OF THE VARI-Z POWER METER--..-.- 36

VI . IMPLEMENTATION OF A VARI-Z POWER METER BY A

SINGLE COUPLER -...................... 42

VII. MEASUREMENT OF SMALL VALUES OF $n_{\mathrm{a}^{-\ldots \ldots}} \ldots \ldots$

VI I I . SUMMARY $\ldots \ldots \ldots$

IX. ACKNOWLEDGMENT - $\ldots \ldots \ldots$

X. REFERENCES - . $\ldots \ldots \ldots \ldots$

APPENDIX I

APPENDIX II _........... 57

APPENDIX III $\ldots \ldots \ldots$

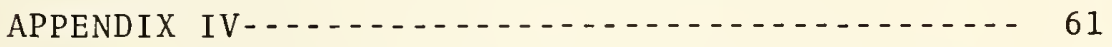

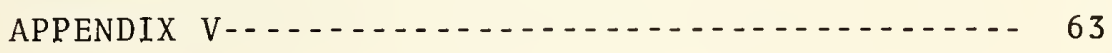


Figure 1. Basic Circuit for Defining $\mathrm{P}_{\mathrm{g}}, \mathrm{P}_{\mathrm{g} \ell}, \mathrm{M}_{\mathrm{g} \ell^{-\ldots .-}}$

Figure 2. Circuit for Discussion of $\mathrm{M}_{\mathrm{g} l}$ Measurement in Conjunction with an Output Monitor-...-.-

Figure 3. Addition of a Second Coupler to Provide for Measurement of $\mathrm{M}_{\mathrm{gl}}$

Figure 4. Illustrating the Relationships Among $R, R_{C}$, $\frac{b_{3}}{b_{4}}$

Figure 5. An Alternate Application for the Measurement of $\mathrm{M}_{\mathrm{gl}}$

Figure 6. Complete Instrumentation for Alternate $\mathrm{M}_{\mathrm{gl}}$

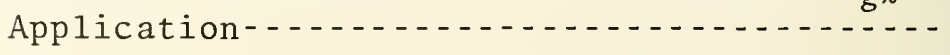

Figure 7. Basic Circuit for Discussion of 2-port App1ications-........................

Figure 8. Basic System for Measurement of $\eta_{a \ell}, \eta_{a}, q_{g a}$,

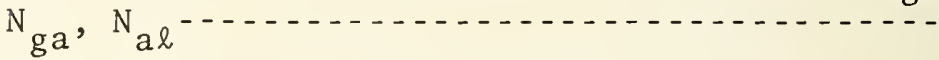

Figure 9. Alternative System, with Tuners, for

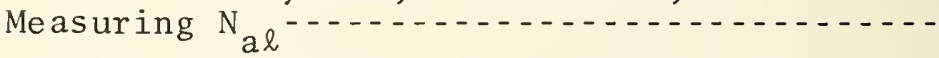

Figure 10. A "Variable-Impedance" Power Meter for Measuring $\mathrm{P}_{\mathrm{g}}$

Figure 11. Addition of a Lossless (LL) Two-Port to

Provide a General Analysis.............

Figure 12. Alternative Form of Vari-z Power Meter-..- 39

Figure 13. Use of 3-port as a Vari-z Power Meter-...-- 43

Figure 14. Several Specific 3-port, Vari-z Power Meter

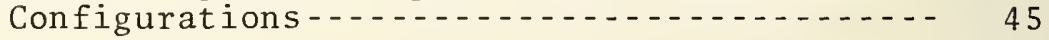

Figure 15. Circuit for Measuring Small Values of $\eta_{a^{-\ldots}} 48$

Figure 16. Circuit for Further Discussion of "Alternate"

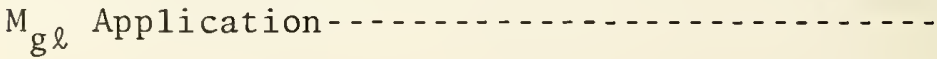




\title{
THEORY OF UHF AND MICROWAVE MEASUREMENTS USING THE POWER EQUATION CONCEPT
}

\author{
by
}

\author{
Glenn F. Engen
}

\section{ABSTRACT}

Theoretical considerations indicate that, in addition to other advantages, UHF and microwave measurements based on the power equation concept should exhibit reduced sensitivity to certain connector imperfections. This has now been experimentally confirmed in a number of laboratories, and interest in these methods is increasing. The previously described measurement techniques, for implementing this concept, have relied heavily upon tuning procedures, while current trends are towards automation where tuning is impractical if not impossible.

By assuming a phase detection capability (such as is found in automated systems) it is possible to eliminate the tuning requirement. Moreover, this generalization has made it possible to summarize the earlier results in a compact form. In addition, this paper includes a number of new measurement ideas.

It is expected that this report will serve as a major reference in the continuing development of detailed measurement procedures which exploit the power equation concept.

Key Words: Microwave; Microwave measurements; Power equation; Power measurement; Terminal invariant.

\section{INTRODUCTION}

Although the initial acceptance has been rather slow, recent laboratory confirmations [1] ${ }^{1},[2]$, of the theoretically

${ }^{1}$ The figures in brackets [ ] represent literature references at the end of this paper. 
predicted benefits of the power equation [3] methods, have stimulated a growing interest. This paper will present an important extension to the basic theory, namely the theoretical basis for some additional measurement techniques, in which a key feature is the elimination of the tuning adjustment. Ordinarily, at radio-frequencies, it is much easier to measure the amplitudes of the associated parameters (e.g. $v$, i, etc.) than the phase. In the microwave region, phase measurements have usually been achieved by conversion to a lower frequency. If one reviews the past two decades, it will be recognized that only amplitude detection or measurement capability was assumed in a majority of the microwave measurement techniques developed and proposed. Presumably this restriction on the assumed detection process was motivated, to a substantial degree, by the desire to avoid the complexity of the phase measurement process. During the latter part of this era, a variety of tuning procedures were developed such that, for example, one could start with a pair of arbitrary directional couplers and tuners, and "construct" an ideal reflectometer [4]. Tuning procedures were also developed to satisfy a variety of other criteria. These tuning methods generally provided a significant improvement in accuracy and the need for phase information was largely suppressed. 
Unfortunately, these tuning adjustments were usually frequency sensitive, often time consuming, and in the development of automated, stepped frequency measurement systems, these tuning procedures were eliminated, but at the price of re-introducing a phase detection capability. ${ }^{2}$

The techniques, which have been described to date, for use in effecting measurement via the power equation concept, have also relied heavily upon tuning procedures. In some cases, a substantial simplification in these procedures has been realized. These methods have the advantage of permitting a substantial improvement in the accuracy potential ${ }^{3}$ of many existing calibration systems which do not possess a phase detection capability.

On the other hand it must be recognized that there is, today, a substantial trend towards automation, and phase detection capabilities in particular. As was the case in the conventional approach, the availability of phase information permits the elimination of tuning requirements in measurements via the power equation concept.

It of course is obvious that the relative merit of any model, for describing the real world, rests to a large degree

\footnotetext{
${ }^{2}$ It must be emphasized that the absence of tuning requirements in existing automated systems rests solely on this phase detection feature.

${ }^{3}$ For example: relaxation of precision connector requirements, explicit accounting for mismatch corrections, etc.
} 
upon the ease (or difficulty) with which the parameters upon which it is based may be evaluated or measured. As already noted, this paper will provide the theoretical basis for a collection of measurement techniques which exploit the power equation concept. This will be done from a broader base than previously employed and include the prior results as special cases. (These will be noted as the theory is developed.) In addition to the elimination of the tuning requirement in the existing methods, this paper will also include a number of other techniques which have no counterpart in the existing art.

A key feature of the power equation concept is that it retains its validity in non-uniform waveguide systems. On the other hand, the measurement techniques developed to date (including those to be described in this paper) require that the waveguide in question be a "reasonable" approximation to a single mode structure. (In practice this means that the cross section must not be allowed to approach those dimensions which represent either cut-off or multimode propagation.) A measurement technique which satisfies the terminal invariant (power equation) criteria must also be valid in the limit of an ideal waveguide. For this reason, it has proven convenient to utilize the existing microwave circuit description in the development of measurement procedures. At the same time, 
however, it must be emphasized that the concepts of reflectionless termination, directivity, VSWR, and impedance generally have no meaning in the power equation context. It is thus necessary to work within the following constraints.

1) The different components, waveguide junctions, etc., which comprise the measurement system are of arbitrary parameters. (This does not mean, however, that all junctions are equally satisfactory for a given application! In general, one uses the circuit theory to recognize a junction whose properties are approximately optimum for a given application. For example, where a directional coupler is specified in what follows, one should understand this to mean a three-port whose parameters approximate those of an ideal device, etc.)

2) The remaining tools at one's disposal include a terminating power meter (of unknown impedance) which indicates net power and an adjustable waveguide short, of unknown phase angle. (Equivalently, one has a variable, or collection of fixed reactances whose values are unknown.)

3) In the case of a multi-arm waveguide junction (eg "reflectometer") it is possible to provide the "sidearm" with detectors which indicate relative amplitudes (only) and phase difference (optional). 
Because the "tools" noted in (2) above satisfy the terminal invariant criteria, it should be intuitively evident that the same will be true of measurement techniques which are derived therefrom. A more complete discussion is given in [5].

In the interests of economy it will only be possible to present a broad theoretical base. It is anticipated that this paper will become a reference document for the development of detailed measurement procedures. This paper will build on the general introduction al ready given in [3], [5] and include only enough background material to ensure continuity. 


\section{I. MEASUREMENT OF MISMATCH}

Referring to figure 1 , the system is described by the equation,

$$
\mathrm{P}_{\mathrm{g} \ell}=\mathrm{P}_{\mathrm{g}} \mathrm{M} \mathrm{gl}
$$

where $\mathrm{P}_{\mathrm{g}}$ is the available power of the generator, $\mathrm{P}_{\mathrm{g} l}$ is the net power delivered to the load, and $\mathrm{M}_{\mathrm{gl}}$ is defined by ( 1 ). The parameter, $M_{g l}$, ranges between zero and unity, and expresses to what extent the (impedance) conditions for maximum power transfer are satisfied.

At this point a brief comment on the notation is desirable. Wherever a single subscript is employed (eg. $\mathrm{P}_{\mathrm{g}}$ ), this indicates that the parameter in question is a function only of a single component (eg., generator). A double subscript (eg., $\mathrm{P}_{\mathrm{gl}}, \mathrm{M}_{\mathrm{gl}}$ ) is used where the parameter is a function of two or more components (eg., generator and load). This scheme will be further developed in the section which follows.

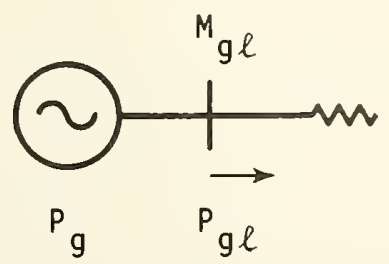

Figure 1. Basic Circuit for Defining $\mathrm{P}_{\mathrm{g}}, \mathrm{P}_{\mathrm{gl}}, \mathrm{M}_{\mathrm{gl}}$ 
It is common practice, in measurement applications at least, to provide the generator with an output monitor in the form of a directional coupler and sidearm power detector. If one agrees to interpret the sidearm power as a measure of the generator level, it has been shown [6] that the parameters of the "equivalent" generator, referred to port 2 , in figure 2 , are determined by the coupler parameters and independent of the actual signal source. The measurement of $\mathrm{M}_{\mathrm{gl}}$ will first be discussed in this context.

Referring to figure 2 , if one assumes the coupler is terminated by a load of arbitrary reflection coefficient, $\Gamma_{\ell}$, one can write, ${ }^{4}$

$$
P_{g \ell}=\left|b_{2}\right|^{2}\left(1-\left|\Gamma_{\ell}\right|^{2}\right)
$$

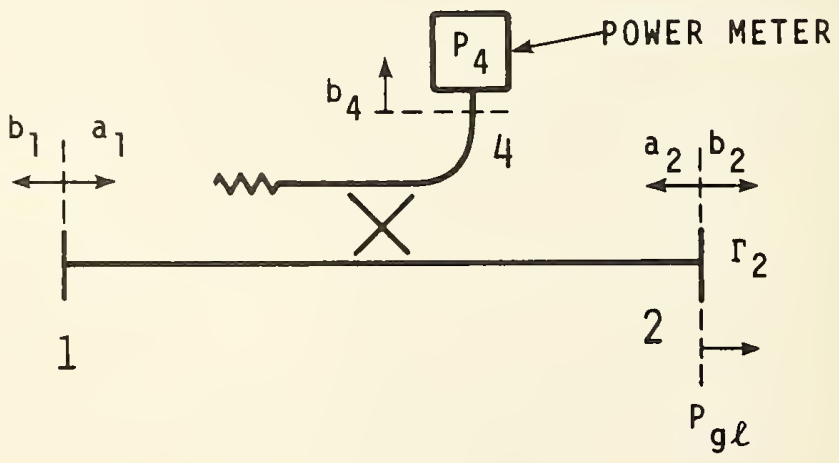

Figure 2. Circuit for Discussion of $\mathrm{M}_{\mathrm{g} l}$ Measurement in Conjunction with an Output Monitor.

\footnotetext{
"The "characteristic" impedance is chosen to equal unity.
} 
where $b_{2}, a_{2}$ are the emergent and incident wave amplitudes at port 2 , and $\Gamma_{\ell}=a_{2} / b_{2}$.

The wave amplitude, $b_{4}$, in the sidearm 4 is a linear function of $a_{2}, b_{2}$ :

$$
\mathrm{b}_{4}=\mathrm{Ca}_{2}+\mathrm{Db}_{2},
$$

and $a_{2}=b_{2} \Gamma_{\ell}$, so that:

$$
\mathrm{P}_{4}=\left|\mathrm{b}_{4}\right|^{2}=\left|\mathrm{b}_{2}\right|^{2}\left|\mathrm{C} \Gamma_{\ell}+\mathrm{D}\right|^{2} \text {. }
$$

Equations (2), (4) may now be combined to yield,

$$
\mathrm{P}_{\mathrm{gl}}=\frac{\mathrm{P}_{4}\left(1-\left|\Gamma_{\ell}\right|^{2}\right)}{|\mathrm{D}|^{2}\left|1+\frac{\mathrm{C}}{\mathrm{D}} \Gamma_{\ell}\right|^{2}},
$$

and with further manipulation (5) may be written:

$$
P_{g \ell_{l}}=P_{4}\left(|D|^{2}\left(1-\left|\Gamma_{g}\right|^{2}\right)\right)^{-1}\left(1-\left|\frac{\Gamma_{\ell}-\Gamma_{g}^{*}}{1-\Gamma_{\ell} \Gamma_{g}}\right|^{2}\right),
$$

where,

$$
\Gamma_{\mathrm{g}}=-\frac{\mathrm{C}}{\mathrm{D}},
$$

and moreover, $\Gamma_{g}$ is the reflection coefficient of the equivalent generator ${ }^{5}$ associated with the directional coupler.

By inspection, $\mathrm{P}_{\mathrm{g} \ell}$ is a maximum when $\Gamma_{\ell}=\Gamma_{\mathrm{g}}^{*}$ (which of course is only to be expected if $\Gamma_{g}$ indeed represents the source reflection coefficient). By comparison with eq. (1),

${ }^{5}$ Ordinarily, the equation for a source is written, $\mathrm{b}_{2}=\mathrm{b}_{\mathrm{g}}+\mathrm{a}_{2} \Gamma_{\mathrm{g}}$ where $\mathrm{b}_{\mathrm{g}}$ is characteristic of the generator. Equation (3) may be written, $b_{2}=b_{4} / D-a_{2}(C / D)$. By analogy, $\mathrm{b}_{4} / \mathrm{D}$ becomes the generator amplitude $\left(\mathrm{b}_{\mathrm{g}}\right)$ so that $\Gamma_{\mathrm{g}}=-\mathrm{C} / \mathrm{D}$. 


$$
\mathrm{P}_{\mathrm{g}}=\mathrm{P}_{4}\left[|\mathrm{D}|^{2}\left(1-\left|\Gamma_{\mathrm{g}}\right|^{2}\right)\right]^{-1} \text {. }
$$

The factor $\left[|D|^{2}\left(1-\left|\Gamma_{g}\right|^{2}\right)\right]^{-1}$ is a property only of the coupler-sidearm detector, and represents a parameter of some importance in power calibration since its product with $\mathrm{P}_{4}$ determines the available power. It is designated by the symbol $\mathrm{K}_{\mathrm{A}}$. The immediate concern of this section, however, is in the mismatch factor, $\mathrm{M}_{\mathrm{gl}}$. Again by comparison with (1),

$$
M_{g l}=1-\left|\frac{\Gamma_{l}-\Gamma_{g}^{*}}{1-\Gamma_{\ell} \Gamma_{g}}\right|^{2} \text {. }
$$

The measurement of $\mathrm{M}_{\mathrm{g} l}$ calls for the addition of a second coupler, as shown in figure 3, such that a four-arm junction is obtained, and of which the initial directional coupler and sidearm detector present a sub-assembly. By

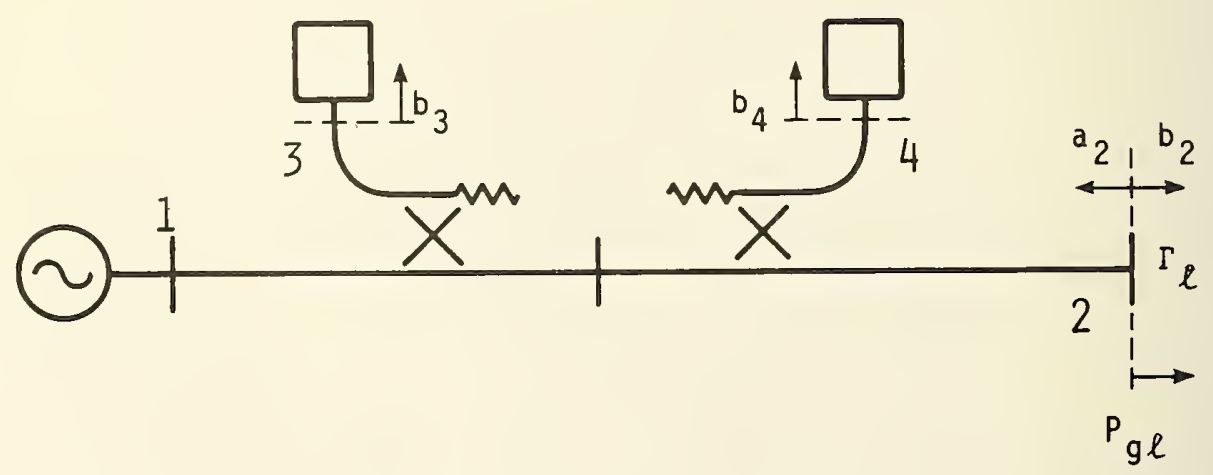

Figure 3. Addition of a Second Coupler to Provide for Measurement of $\mathrm{M}_{\mathrm{gl}}$ 
analogy with (3), one can write, 6,7

$$
\mathrm{b}_{3}=\mathrm{Aa}_{2}+\mathrm{Bb}_{2} \text {, }
$$

and the ratio of (10) and (2) yields,

$$
\frac{\mathrm{b}_{3}}{\mathrm{~b}_{4}}=\frac{\mathrm{A} \Gamma_{\ell}+\mathrm{B}}{\mathrm{C} \Gamma_{\ell}+\mathrm{D}}
$$

In contrast with most of the prior treatments, it is assumed that a detection capability exists such that the complex ratio $\frac{b_{3}}{b_{4}}$ may be measured. (In practice this may be effected in a variety of ways, the specific details are outside the scope of this paper.) Let $\Gamma_{\ell}=e^{i \theta}$, where $\theta$ is arbitrary. Then, with a little manipulation, (11) may be written,

$$
\frac{b_{3}}{b_{4}}=\frac{A e^{i \theta}+B}{C e^{i \theta}+D}=\frac{B D^{*}-A C^{*}}{|D|^{2}-|C|^{2}}+\frac{(A D-B C) e^{i \theta}\left(D^{*}+C^{*} e^{-i \theta}\right)}{\left(|D|^{2}-|C|^{2}\right)\left(D+C e^{i \theta}\right)} .
$$

By inspection, if $\theta$ is permitted to vary, the locus of $\frac{b_{3}}{b_{4}}$ in the complex plane is a circle with center $R_{C}$, and radius $\mathrm{R}$ where, ${ }^{8}$

${ }^{6}$ The terminology has been chosen in such a way as to permit a ready comparison with a number of earlier results.

${ }^{7}$ Here it will be recognized that the values of $\mathrm{A}$ and $\mathrm{B}$ depend upon both couplers. (Note that the "original" coupler may be considered an extension of the main arm of the coupler which has just been added.) By contrast, C, D, continue to depend only on the "original" coupler parameters. This conclusion is implicit in the above development, a more detailed proof is found in [7].

${ }^{8}$ Note that the ratio $\left(D^{*}+C^{*} e^{-i \theta}\right) /\left(D+C e^{i \theta}\right)$ has a magnitude of unity . 


$$
\begin{aligned}
R_{C} & =\frac{B D^{*}-A C^{*}}{|D|^{2}-|C|^{2}}, \\
R & =\left|\begin{array}{c}
A D-B C \\
|D|^{2}-|C|^{2}
\end{array}\right| .
\end{aligned}
$$

This relationship is indicated in figure 4. In particular it should be noted that $R_{c}$ is a complex parameter.

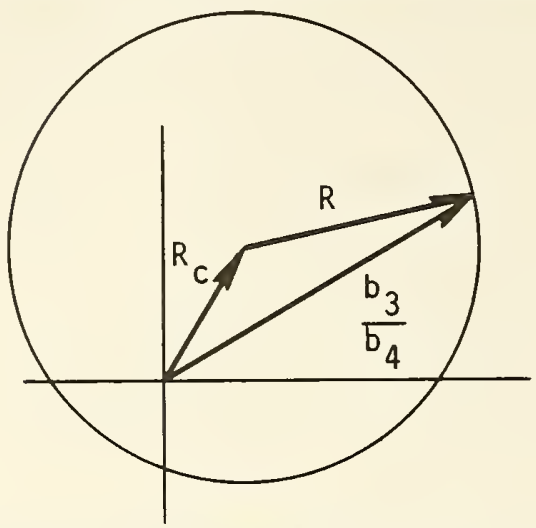

Figure 4. Illustrating the Relationships Among $R, R_{c}, \frac{b_{3}}{b_{4}}$

The measurement of $\mathrm{M}_{\mathrm{g}}$ requires, in part, a determination of $R_{C}$, $R$. This may, quite obviously, be done in a variety of ways. For example, the values of $\frac{b_{3}}{b_{4}}$ may be observed for three values of $\theta$ (offset shorts, "opens," reactances, etc.), and the circular locus determined from the standard formulas of analytic geometry. Alternatively, if a moving short is used, inspection of figure 4 indicates that if $\theta$ is adjusted such that $\left|\frac{b_{3}}{b_{4}}\right|$ is a maximum,

$$
\arg R_{c}=\arg \frac{b_{3}}{b_{4}},
$$




$$
\left|\mathrm{R}_{\mathrm{c}}\right|+\mathrm{R}=\left|\frac{\mathrm{b}_{3}}{\mathrm{~b}_{4}}\right|_{\max },
$$

while if $\theta$ is adjusted such that $\left|\frac{b_{3}}{b_{4}}\right|$ is a minimum,

$$
R-\left|R_{c}\right|= \pm\left|\frac{b_{3}}{b_{4}}\right|_{\text {min }},
$$

where the upper sign is used if, as in figure 4, the argument of $\frac{b_{3}}{b_{4}}$ now differs from the previous value by $\pi$. If, on the other hand, the origin is outside the circle, the argument of $\frac{b_{3}}{b_{4}}$ will have the same value for both maximum and minimum values of $\left|\frac{b_{3}}{b_{4}}\right|$ and the lower sign should be used. For the systems considered in this paper, $R>\left|R_{C}\right|$ and this is assumed in what follows. (See Appendix 5). Equations (15), (16), (17) may be easily inverted to obtain $R_{c}$ and $R$.

In addition to the measurement of $R_{C}$, $R$, the determination of $M_{g l}$ requires a measurement of $\frac{b_{3}}{b_{4}}$ when $\Gamma_{l}$ pertains to the specified load for which $\mathrm{M}_{\mathrm{g} l}$ is required. This will be designated by w. Evidently:

$$
w=\frac{A \Gamma_{\ell}+B}{C \Gamma_{\ell}+D} .
$$

Equation (18) may be solved for $\Gamma_{\ell}$. This together with (7) leads to

$$
\frac{\Gamma_{\ell}-\Gamma_{g}^{*}}{1-\Gamma_{\ell} \Gamma_{g}}=\frac{\left(|D|^{2}-|C|^{2}\right) w-\left(B D^{*}-A C^{*}\right)}{A D-B C}
$$


and this may be combined with (9), (13), (14) to yield,

$$
M_{g l}=1-\frac{\left|w-R_{C}\right|^{2}}{R^{2}} \text {. }
$$

Equation (20) is the desired relationship.

This result explicitly demonstrates several important features of the power equation formulation. In principle, either (9) or (20) could serve as the basis for a determination of $\mathrm{M}_{\mathrm{gl}}$. The former, however, calls for a measurement of $\Gamma_{\mathrm{g}}$ and $\Gamma_{\ell}$; this represents the "conventional" approach, and generally involves impedance standards, precision slotted lines, or directivity considerations. Equation (20) demonstrates, on the other hand, that it is possible to avoid the impedance measurement routine; it is only necessary that $w, R_{C}$, and $R$ be measured. In particular it should be noted that this result is valid for "imperfect" couplers and loads of arbitrary impedance. Moreover, the determination of $R_{c}$ and $R$ does not require that the phase of the sliding (or offset) shorts be known. ${ }^{9}$ The measurement method thus satisfies the "terminal invariant" criteria [5].

In the prior art, a tuning transformer was included between the two couplers. This was adjusted either for $\mathrm{b}_{3}=0$ with the load $\Gamma_{\ell}$ connected, or such that $\left|\frac{b_{3}}{b_{4}}\right|$ was a constant with respect to a moving short at port 2. From

${ }^{9}$ In terms of $v$, i description, this means that the terminations should be "completely reactive." The value of reactance need not be known. 
the foregoing discussion it is apparent that the first condition leads to $\mathrm{w}=0$, the second to $\mathrm{R}_{C}=0$. In either event the phase detection is not required.

If $w=0$, the measurement of $M_{g l}$ calls for observing $\left|\frac{b_{3}}{b_{4}}\right|_{\max }$ and $\left|\frac{b_{3}}{b_{4}}\right|_{\min }$ in response to a sliding short. Then,

$$
M_{g l}=1-\frac{\left|R_{c}\right|^{2}}{R^{2}}=1-\left(\frac{\left|\frac{b_{3}}{b_{4}}\right|_{\max }-\left|\frac{b_{3}}{b_{4}}\right|_{\min }}{\left|\frac{b_{3}}{b_{4}}\right|_{\max }+\left|\frac{b_{3}}{b_{4}}\right|_{\min }}\right)^{2} \text {. }
$$

On the other hand, if $R_{c}=0$, it suffices to observe $\left|\frac{b_{3}}{b_{4}}\right|$ with the load and a short connected. In this case,

$$
M_{g l}=1-\frac{|w|^{2}}{R^{2}}=1-\frac{\left|\frac{b_{3}}{b_{4}}\right|_{\Gamma_{\ell}}^{2}}{\left|\frac{b_{3}}{b_{4}}\right|_{\text {short }}^{2}} .
$$

A major application of the foregoing treatment is in the area of power calibration. To briefly summarize, the power output, $\mathrm{P}_{\mathrm{g} \ell}$, from the coupler in figure 2 , may be written,

$$
\mathrm{P}_{\mathrm{gl}}=\mathrm{P}_{4} \mathrm{~K}_{\mathrm{A}} \mathrm{M}_{\mathrm{gl}} \text {, }
$$

where $\mathrm{P}_{4}$ is the sidearm power, $\mathrm{K}_{A}$ is a property of the couplersidearm power meter combination and $M_{g l}$ is a mismatch factor whose measurement has been described above. If the termination is a "standard" power meter, its reading determines $\mathrm{P}_{\mathrm{g} \ell}$, which, together with the associated values of $\mathrm{P}_{4}$ and $\mathrm{M}_{\mathrm{g} \ell}$, determines $\mathrm{K}_{\mathrm{A}}$. When the termination is another power 
meter, its reading may be compared with $\mathrm{P}_{\mathrm{gl}}$ and thus its calibration obtained.

It will be recalled that the reflection coefficient, $\Gamma_{g}$, associated with the directional coupler was the negative of the ratio of $\mathrm{C}$ to $\mathrm{D},(7)$. Moreover, these parameters are independent of the properties of the second coupler which was added to permit the measurement of $\mathrm{M}_{\mathrm{gl}}$. Indeed, unless this were true, of C/D at least, $\Gamma_{g}$ would not be a property of the original coupler alone. It will next be instructive to consider a different combination of components, but in which the foregoing criteria are only partially satisfied.

There are a number of practical situations in which this alternate configuration is useful. One example is in the comparison of two noise sources via radiometric techniques [8]. Another example is in the "receiving end" of an antenna calibration setup [9]. In these applications, and others, the use of a directional coupler to monitor the "source" behavior is obviously impractical, if not impossible. It may be possible, however, to add a (first) directional coupler to the detector input as shown in figure 5. Ordinarily the coupling ratio, measured in $d B$, should be 20 or more. To complete the system, the "second" directional coupler and other components as shown in figure 6 are added. 


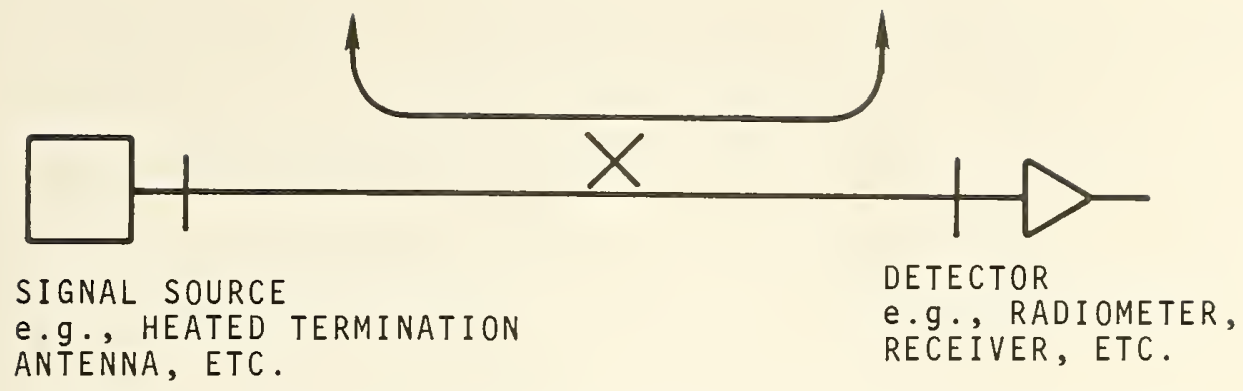

Figure 5. An Alternate Application for the Measurement of $\mathrm{M} g$ l

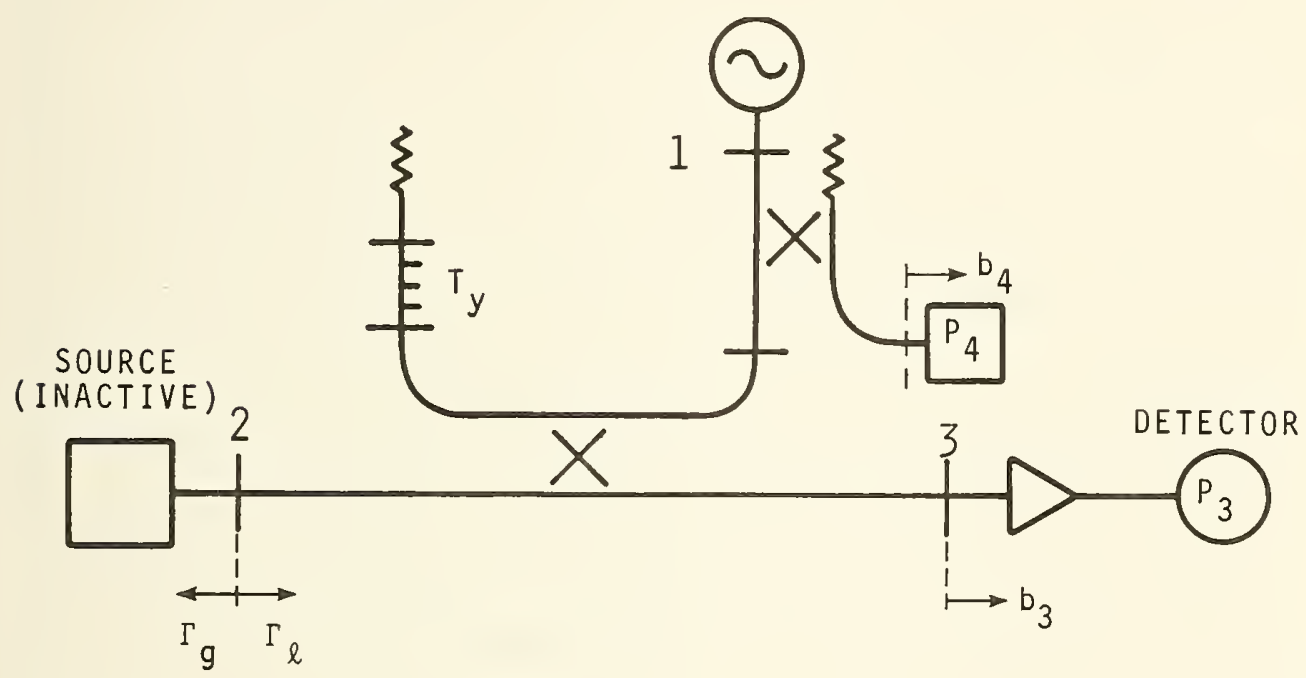

Figure 6. Complete Instrumentation for Alternate $\mathrm{M}_{\mathrm{g} l}$
Application

Now it is assumed that the "active" element in the source may be "turned off" without affecting $\Gamma_{g}$. In the case of the antenna, for example, the illuminating source is disconnected, or the antenna pointed in a different direction. In the noise measurement application, it may be that the radiometer design is such as to recognize the 
difference between a cw and noise source. Or, the level of the cw signal in figure 6 may be such as to completely mask the noise power input. Alternatively, the radiometer input may contain isolators or similar components, ahead of the signal amplifying elements, which determine the "detector" impedance properties. When this is the case, it may be desirable to switch in an auxiliary detector, following the isolator, and replacing the amplifier for the measurement of $\mathrm{M}_{\mathrm{gl}}$.

In a formal sense, the only difference between the configurations of figures 6 , and 3 , is a matter of terminology and in the resultant values for the parameters A, B, C, D. With regard to terminology, the roles of $\Gamma_{g}$ and $\Gamma_{\ell}$ have been reversed. In particular the terminating "load" in figure 6 now has the reflection coefficient " $\Gamma_{g}$," while the ratio -C/D becomes " $\Gamma_{\ell} . "$ Moreover, the parameters C, D are now dependent upon both couplers, If, however, the coupling ratio for the "first" coupler is "large" (20 dB or greater) the ratio C/D has only a weak dependence upon the properties of the "second" coupler.

The validity of this statement may be recognized with the help of (3). In general (3) is valid under all modes of operation. It is convenient, therefore, to assume that excitation has been applied via port 2 in figure 6 , and that port 1 has been terminated such that $b_{4}=0$. Then, 


$$
\frac{b_{2}}{a_{2}}=\Gamma_{\ell}=-\frac{C}{D},
$$

which provides an explicit demonstration of an earlier assertion. Because the coupling between the primary and secondary line is "small," it may now be recognized that the input reflection coefficient at port 2 will have only a weak dependence upon the characteristics of the second coupler.10 The addition of these components thus represents little more than an extension of the input port of the original detector.

The measurement of $\mathrm{M}_{\mathrm{g} l}$ may again be obtained in several ways, as previously described. For example, $\mathrm{T}_{\mathrm{y}}$ may be adjusted such that the detector output vanishes when excitation is applied via port 1 , and the "source" is connected to port 2 but "turned off." Following this adjustment, a moving short is connected to port 2 , and the maximum and minimum values of $\left|\frac{b_{3}}{b_{4}}\right|$ are observed and substituted into (21). Alternatively, $\mathrm{T}_{\mathrm{y}}$ may be adjusted such that $\left|\frac{\mathrm{b}_{3}}{\mathrm{~b}_{4}}\right|$ is a constant in response to the short motion, in this case (22) becomes the appropriate equation. Finally, it may be possible to obtain the argument of $\frac{b_{3}}{b_{4}}$, in this event (20) applies and the tuning operation is not required.

${ }^{10}$ For example, if ideal components are assumed, $\Gamma_{\ell}=0$. If the second coupler is replaced by a "short," the value of $\left|\Gamma_{\ell}\right|$ becomes .01. 
Before concluding this discussion, several other items are worthy of mention. Referring once more to figure 6 , the contribution of the "second" directional coupler is rather small, other than providing the phase reference, and can usually be deleted if desired.1 ${ }^{1}$ In addition to the questions already considered, it is also recognized that the operation of the tuner $\mathrm{T}_{y}$ will have a small but ordinarily negligible effect upon the power transmission "efficiency" between port 2 and the detector input. These questions will be considered in greater detail in Appendix I.

Finally, there will undoubtedly be "field" situations where the permanent introduction of these couplers, etc., is untenable. In this case it is possible to measure $\mathrm{P}_{\mathrm{g} l}$ by a "variable-impedance" power meter which has been adjusted to duplicate the required load impedance. Methods for implementing this and measuring $\mathrm{P}_{\mathrm{g}}$ will be described in following sections. This also permits the determination of $\mathrm{M}_{\mathrm{g} \ell}$ via (1).

\section{I I . TWO-PORT MEASUREMENTS}

The extension of the power equation methods to describe two-ports (attenuators) begins with the system shown in figure 7 , and the equation,

TIf one postulates that the sidearm auxiliary signal source is stable and that it is replaced by a passive termination of identical impedance, the "second" coupler contributes nothing other than the "phase reference" and may be deleted when the tuning is employed. In real life the instability of the signal source affects only the difference between $M_{g l}$ and unity, while the failure to satisfy the impedance gl condition is "attenuated" by the coupling ratio. 


$$
\mathrm{P}_{\mathrm{gl}}=\mathrm{P}_{\mathrm{g}}^{\mathrm{M}} \mathrm{ga}_{\mathrm{a} \ell},
$$

where $n_{a l}$ is the efficiency of the attenuator for the given load, and the other terms have been previously defined. The validity of this result is easily established. In particular, $M_{g a}$ represents the mismatch factor between the generator and the attenuator-load combination. The product $\mathrm{P}_{\mathrm{g}}^{\mathrm{M}} \mathrm{ga}$ thus represents the net power delivered to the attenuator, while $n_{\text {al }}$ (by definition) is the ratio of the power output of the attenuator $\left(\mathrm{P}_{\mathrm{g} \ell}\right)$ to the power input $\left(\mathrm{P}_{\mathrm{g}} \mathrm{M}_{\mathrm{ga}}\right)$. In this description the attenuator is "combined" with the load to yield a new "load" such that (1) applies at terminal 2 in figure 7 .

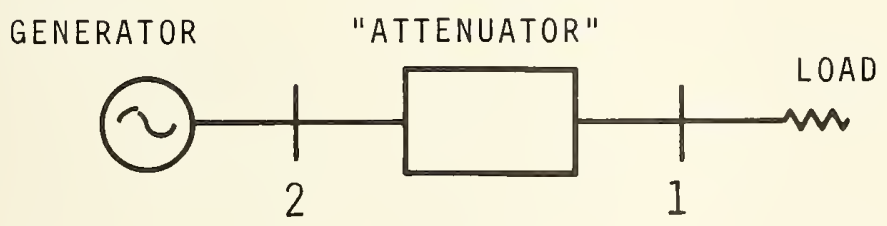

Figure 7. Basic Circuit for Discussion of 2-port Applications

Alternatively, it is possible to write,

$$
\mathrm{P}_{\mathrm{gl}}=\mathrm{P}_{\mathrm{g}} \mathrm{ga}_{\mathrm{a}} \mathrm{M}_{\ell} \text {, }
$$

where $\mathrm{P}_{\mathrm{g} \ell}, \mathrm{P}_{\mathrm{g}}$ are already defined, $\mathrm{P}_{\mathrm{g}} \mathrm{q}_{\mathrm{ga}}$ is the available power from the generator-attenuator combination (at terminal 
1 ), and $\mathrm{M}_{\mathrm{al}}$ is the mismatch factor between this "modified generator" and the load. Here it is noted that (1) has been applied at terminal 1 rather than 2 . Moreover the parameter $\mathrm{q}_{\mathrm{ga}}$ is the ratio between the available power at terminal 1 and the available power at terminal 2. By contrast, $n_{a}$ is a ratio between net powers. In spite of this distinction, when reciprocity is satisfied, $\mathrm{q}_{\mathrm{ga}}$ and $\eta_{\mathrm{al}}$ are related in a rather simple manner. In figure $7, \eta_{a l}$ is defined in conjunction with an assumed power flow from terminal 2 to terminal 1 and is a function of the load, but not the source, impedance. If one assumes the active element associated with the generator in figure 7 is "turned off," such that it becomes a passive load of identical impedance properties, and excitation is applied via port 1 , the "efficiency" for power flow from terminal 1 to terminal 2 is equal to $\mathrm{q}_{\mathrm{ga}}$, and is a function of the generator impedance.

It has also proven useful to introduce the maximum value of $\eta_{a l}$ (as a function of load impedance) by $\eta_{a}$, and the parameter $\mathrm{N}_{\text {al }}$ such that

$$
\eta_{\mathrm{a} \ell}=\eta_{\mathrm{a}^{\mathrm{N}}} \mathrm{a} \text {, }
$$

where $\mathrm{N}_{\mathrm{a} \ell}$ is another type of mismatch factor which again varies between zero and unity. Moreover, if reciprocity is satisfied, the maximum value of $q_{g a}$ will also equal $\eta_{a}$ and it is possible to write

where $\mathrm{N}_{\mathrm{ga}}$ is defined by (28).

$$
q_{g a}=\eta_{a}{ }_{g a},
$$


The parameters $\mathrm{N}_{\mathrm{a} \ell}$, $\mathrm{N}_{\text {ga }}$ thus express to what extent $\eta_{a \ell}$ and $q_{g a}$ differ from their maximum possible value, $n_{a}$. Loosely speaking, the values of these parameters are determined by the impedance conditions found at terminals 1 and 2 respectively. The same, however, could be said of $\mathrm{M}_{\mathrm{al}}$ and $\mathrm{Mga}_{\mathrm{ga}}$. The distinction lies in that $\mathrm{N}_{\mathrm{al}}$ is a function only of the attenuator and load parameters while $\mathrm{M}_{\mathrm{al}}$ also depends, to some extent at least, upon the generator. A similar statement could be made in reference to $\mathrm{N}_{\mathrm{ga}}$ and $\mathrm{M}_{\mathrm{ga}}$. In summary, the "M" type of mismatch depends, to some extent at least, upon all of the components found in the system. The subscripts indicate the two components between which the mismatch is to be evaluated. The subscripts play a similar role in the " $N$ " type of mismatch, but here the functional dependance includes only the two-port on one side of the terminal surface of interest, and all of the components on the other side. With regard to $\eta_{a} v s$. $\eta_{a}$, the former depends only on the two-port while the latter depends upon the load as well. Perhaps in the interests of consistency the term $\mathrm{P}_{\text {gal }}$ should have been introduced, but this has not been deemed desirable. For a further discussion [3] and [5] should be consulted.

The measurement of $\eta_{a \ell}, \eta_{a}, q_{g a}, N_{g a}, N_{a \ell}$ may be conveniently realized by means of the measurement system ${ }^{12}$ shown ${ }^{2}$ The conventional ordering of the directional couplers would be equally convenient in many cases. 
in figure 8 , provided that reciprocity holds and the value of $\mathrm{n}_{\mathrm{a}}$ is not too small. (The measurement problem where these criteria are not satisfied will be considered in a following section.) As compared with figure 7, the "generator" has been replaced by the measurement system of figure 3 . In harmony with the terminology already introduced, the complex ratio $b_{3} / b_{4}$ will be denoted by $w$ when the system is connected as shown in figure 8. In addition the terms $R_{1}, R_{c l}$, and $R_{2}, R_{c 2}$ will represent the parameters of the circular locus obtained with moving or fixed "shorts" connected to ports 1 and 2 respectively.

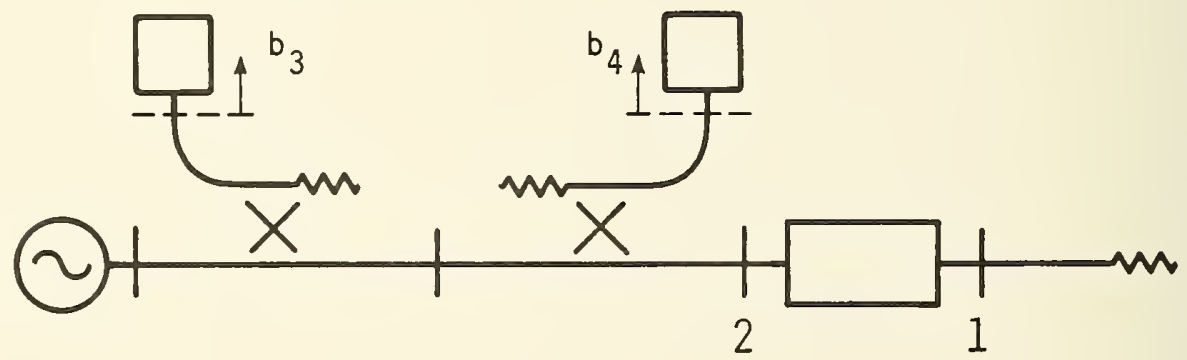

Figure 8. Basic System for Measurement of $\eta_{a l}, \eta_{a}, q_{g a}$, $\mathrm{N}_{\text {ga }}, \mathrm{N}_{\mathrm{al}}$

It has been previously shown [5] that,

$$
q_{g a}=\frac{R_{1}}{R_{2}} .
$$

Together with (8) and (23) this means that the available power from terminal 2 is $\mathrm{P}_{4} \mathrm{~K}_{\mathrm{A}}$, while that from terminal 1 
is $\mathrm{P}_{4} \mathrm{~K}_{\mathrm{A}} \mathrm{R}_{1} / \mathrm{R}_{2}$. This result is of interest in that $\mathrm{q}_{\mathrm{ga}}$ is the one parameter which requires neither phase information, nor tuning to effect its measurement.

An equation for $\eta_{a \ell}$, in terms of $w, R_{1}, R_{c 1}, R_{2}, R_{c 2}$ may now be easily obtained. Since $\mathrm{P}_{\mathrm{gl}}, \mathrm{P}_{\mathrm{g}}$ represent the same values in (25) and (26), it immediately follows,

$$
\mathrm{M}_{\mathrm{ga}} \mathrm{n}_{\mathrm{a} \ell}=\mathrm{q}_{\mathrm{ga}} \mathrm{M}_{\mathrm{a} \ell} \text {. }
$$

By means of (20), the terms $M_{g a}$, $M_{a l}$ may now be evaluated in terms of $w, R_{1}, R_{c 1}$, and $w, R_{2}, R_{c 2}$ respectively; $q_{g a}$ is given by (29) so that:

$$
\eta_{a \ell}=\frac{R_{1}}{R_{2}} \frac{\left(1-\frac{\left|w-R_{c 1}\right|^{2}}{R_{1}^{2}}\right)}{\left(1-\frac{\left|w-R_{c 2}\right|^{2}}{R_{2}^{2}}\right)} .
$$

The value of $n_{a}$ may next be obtained from (31) as follows. In general there will be a unique relationship between $w$ and the load impedance. For some value of load impedance, $\eta_{a}$ will be a maximum; this must be reflected in a corresponding value for $w$. It is therefore sufficient to find the maximum value of (31) as a function of $w$. This computation, the details of which will be found in Appendix II, leads to: ${ }^{13}$

${ }^{13} \mathrm{~A}$ second solution, the reciprocal of that given, is also obtained but of no interest in this context. 


$$
\eta_{\mathrm{a}}=\mathrm{H}-\sqrt{\mathrm{H}^{2}-1} \text {, }
$$

where,

$$
H=\frac{R_{1}^{2}+R_{2}^{2}-\left|R_{c 2}-R_{c 1}\right|^{2}}{2 R_{1} R_{2}} .
$$

If the value of $\eta_{a}$ is small, the following expansion should be used,

$$
n_{a}=F\left[1+F^{2}+2 F^{4}+5 F^{6}+\cdots\right] \text {. }
$$

where

$$
F=\frac{1}{2 H}=\frac{R_{1} R_{2}}{R_{1}^{2}+R_{2}^{2}-\left|R_{c 2}-R_{c 1}\right|^{2}} .
$$

An expression for $\mathrm{N}_{\text {ga }}$ may now be obtained with the help of (28) and (29). From (32),

$$
\begin{aligned}
1 / n_{a} & =H+\sqrt{H^{2}-1}, \\
& =\frac{1}{F}\left[1-F^{2}-F^{4}-2 F^{6}-\cdots\right],
\end{aligned}
$$

so that,

$$
\begin{aligned}
N_{g a} & =\frac{q_{g a}}{\eta_{a}}=\frac{R_{1}}{R_{2}}\left(H+\sqrt{H^{2}-1}\right), \\
& =\left(1-\frac{\left|R_{c 2}-R_{c 1}\right|^{2}}{R_{2}^{2}}+\frac{R_{1}^{2}}{R_{2}^{2}}\right\} \cdot\left(1-F^{2}-F^{4}-2 F^{6} \ldots\right) .
\end{aligned}
$$

In a similar manner, 


$$
\begin{aligned}
N_{a \ell} & =\frac{n_{a \ell}}{n_{a}}=\frac{R_{1}}{R_{2}} \frac{\left(1-\frac{\left|w-R_{c 1}\right|^{2}}{R_{1}^{2}}\right)}{\left(1-\frac{\left|w-R_{c 2}\right|^{2}}{R_{2}^{2}}\right)}\left(H+\sqrt{H^{2}-1}\right), \\
& =\frac{\left(1-\frac{\left|R_{c 2}-R_{c 1}\right|^{2}}{R_{2}^{2}}+\frac{R_{1}^{2}}{R_{2}^{2}}\right\}}{\left(1-\frac{\left|w-R_{c 2}\right|^{2}}{R_{2}^{2}}\right)}\left(1-\frac{\left|w-R_{c 1}\right|^{2}}{R_{1}^{2}}\right)\left(1-F^{2}-F^{4}-2 F^{6}-\ldots\right)
\end{aligned}
$$

As a general rule this collection of measurement techniques is useful only for "large" values of $\eta_{a}$ (i.e. $\left.n_{a}>0.1\right)$. The reason for this limitation is easily explained with the help of figure 8. Loosely speaking, the measurement procedure calls for observation of the change in impedance at port 2 in response to a phasable short at terminal 1 . As $n_{a}$ becomes small, these changes become smaller and are ultimately lost in the noise and instability of the measurement system. In the case of $\eta_{a}$, (31), not only does $R_{1}$ become difficult to measure, but the difference between $W$ and $R_{c l}$ will be smal1 ${ }^{14}$ so that $\left|w-R_{c l}\right| / R_{1}$ becomes indeterminant.

The measurement of $\mathrm{N}_{\mathrm{ga}}$, however, stands in contrast to this general rule. Inspection of (39) indicates that if ${ }^{14}$ Note that as $R_{1} \rightarrow 0$, the impedance at port 2 becomes the same for all terminations and $w=R_{c l}$. 
$\mathrm{R}_{1} \rightarrow 0, \mathrm{R}_{\mathrm{cl}} \rightarrow \mathrm{w}$, and,

$$
\lim _{\eta_{a} \rightarrow 0} N_{g a}=\left(1-\frac{\left|w-R_{c 2}\right|^{2}}{R_{2}^{2}}\right)=M_{g a} \text {. }
$$

This result is to be expected since if $n_{a}=0$ the two-port behaves like a termination.

Because of the limitation on the foregoing techniques, it is necessary to devise alternative procedures when $n_{a}$ is sma11, or when reciprocity is not satisfied. In a following section, this more general problem will be considered.

In the foregoing equations, phase detection is required to evaluate the expressions $\left|w-R_{c 1}\right|,\left|w-R_{c 2}\right|,\left|R_{c 2}-R_{c 1}\right|$. As before, this requirement can be avoided by the use of tuners. For example, the insertion of a tuner between the two couplers in figure 8 permits one to adjust the system such that one of the parameters $w, R_{c 1}, R_{c 2}$, vanishes. This is sufficient for the measurement of $\eta_{a \ell}, \eta_{a}$, and $N_{g a}$. If the phase requirement is to be avoided in the measurement of $\mathrm{N}_{\mathrm{al}}$, however, two of these three parameters must vanish. This may be realized by the addition of a second tuner at terminal 2 in figure 8 . However to avoid interaction in the adjustments, the position of the two couplers should also be exchanged, such that the configuration of figure 9 results. Tuner $\mathrm{T}_{\mathrm{x}}$ (figure 9) may now be adjusted such that $w$ vanishes, and either $R_{c 1}$ or $R_{c 2}$ reduced to zero by use of $\mathrm{T}_{y}$. Alternatively, $\mathrm{T}_{y}$ may be adjusted such that $R_{c 2}$ vanishes and $T_{x}$ used to eliminate $R_{c 1}$. 
In the former case the adjustments are independent provided that they are performed in the given order; in the latter case a small amount of interaction is possible due to losses in $\mathrm{T}_{\mathrm{X}}$.

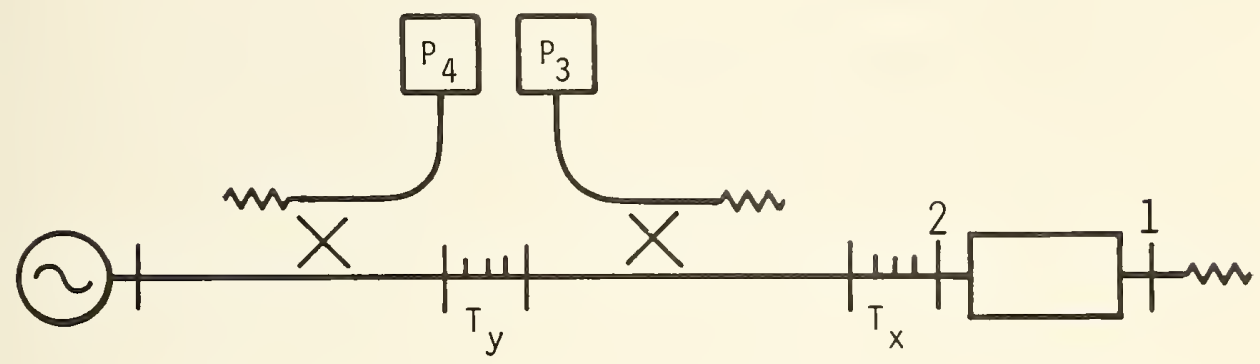

Figure 9. Alternative System, with Tuners, for Measuring Nal

IV. MEASUREMENT OF $\mathrm{P}_{\mathrm{g}}$

The measurement of $\mathrm{P}_{\mathrm{g}}$ in conjunction with a power monitor (directional coupler and sidearm detector) has already been described (cf. (8), (23)). In particular the parameter " $\mathrm{K}_{\mathrm{A}}$ " determines the available power from the monitor output port for a given monitor (sidearm power) indication. It remains to consider the more general problem where the only access to the generator is via its output port.

The measurement of $\mathrm{P}_{\mathrm{g}}$, in this more general context, may be effected by use of a "variable impedance" (vari-z) power meter. This device is comprised of a two-port, one arm of which represents the power meter input, while the other 
is terminated by a variable load. Provided that the two-port efficiency is reasonably large, changes in the variable load impedance will result in impedance variations at the input port. In addition, instrumentation is provided which indicates the net power input $\left(\mathrm{P}_{\mathrm{gl}}\right)$.

Perhaps the most straightforward use of this device is to connect it to the generator of interest, and vary the load impedance until the indicated value of $\mathrm{P}_{\mathrm{g} l}$ is a maximum. Provided that the conjugate of the generator impedance falls within the range of impedance values to which the vari-z power meter can be adjusted, this procedure will yield $\mathrm{P}_{\mathrm{g}}$.

Alternatively, the need for providing arbitrary but unknown impedance values can be avoided in an alternate scheme where the "variable load" takes the form of a moving short. This device is indicated schematically in figure 10. The theory for this alternative application will now be developed; further details for implementing the vari-z power meter will be found in the next section.

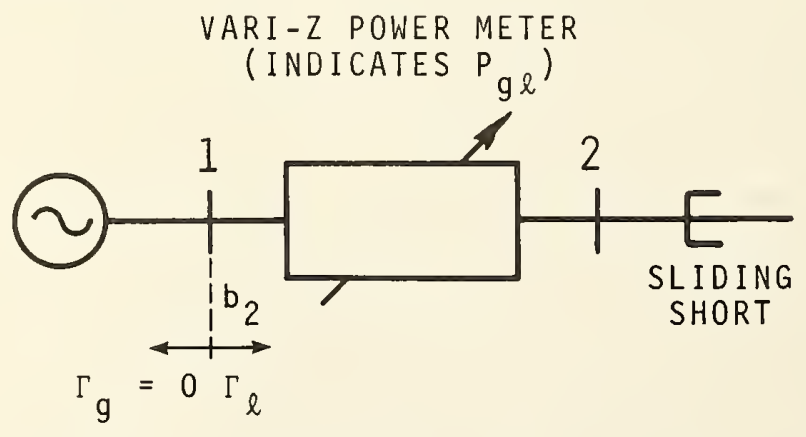

Figure 10. A "Variable-Impedance" Power Meter for Measuring
${ }_{\mathrm{g}}$ 
The two-port parameters will be taken as arbitrary; however as an expedient, an impedance match $\left(\Gamma_{\mathrm{g}}=0\right)$ is assumed for the generator. Although at first this represents a very special case, it is, in fact, possible to derive a measurement technique which is valid for arbitrary values of generator impedance provided that certain "rules" are followed. This represents a powerful analytical tool and perhaps warrants a brief digression in order that the approach is clearly understood.

Referring to figure 11 , a lossless (LL), but otherwise arbitrary, two-port has been inserted between the generator and vari-z power meter. If this lossless two-port is considered as part of the generator, its parameters may be so chosen as to yield arbitrary values of generator impedance, but its presence will not affect the value of $\mathrm{P}_{\mathrm{g}}$.

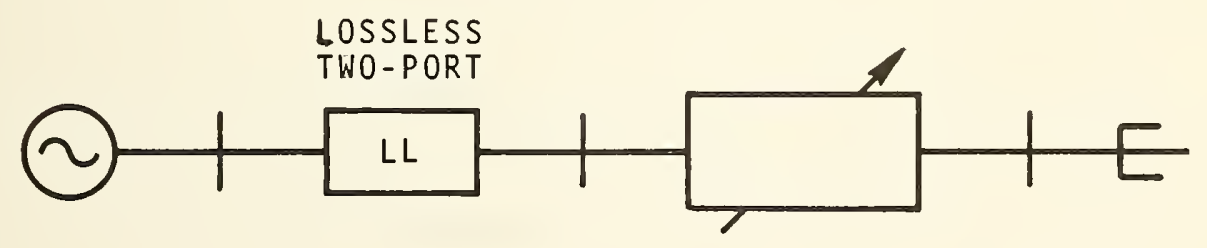

Figure 1l. Addition of a Lossless (LL) Two-Port to Provide a General Analysis 
On the other hand, the lossless two port may also be considered an integral part of the vari-z power meter. Although it introduces an element of indeterminacy into the parameters of the associated two-port, (which are, as yet, unspecified), the addition of this component will not affect the operation (calibration) of the vari-z power meter because of its lossless character.

In order to complete the picture, it is evident that some further information, relative to the vari-z power meter parameters, will be required because a determination of $\mathrm{P}_{\mathrm{g}}$ obviously requires more than the measurement of $\mathrm{P}_{\mathrm{gl}}$ for several unknown values of load impedance. From the foregoing discussion it should be evident, however, that if a method for measuring $\mathrm{P}_{\mathrm{g}}$ when $\Gamma_{\mathrm{g}}=0$ can be devised, and in which on $1 y$ terminal invariant properties of the vari-z power meter are involved, this procedure will work equally well when $\Gamma_{g} \neq 0$. It has already been noted that the specified indication (in terms of net power) satisfies this condition. Referring to figure 10 , it will be assumed that the lossless two-port has been "absorbed" by the power meter. The reflection coefficient, $\Gamma_{\ell}$, presented by the power meter, can be written in the form (cf. (12))

$$
\Gamma_{\ell}=\frac{a e^{i \theta}+b}{c e^{i \theta}+1},
$$


where $a, b, c$ are parameters of the power meter, and $\theta$ is determined by the position of the moving short. For a matched generator, the emergent wave, $b_{2}$, is independent of $\Gamma_{\ell}$, and from (2), $\left|b_{2}\right|^{2}=P_{g}$. Combining this result with (2) and (43) gives,

$$
P_{g l}=P_{g}\left(1-\left|\frac{a e^{i \theta}+b}{c e^{i \theta}+1}\right|^{2}\right) .
$$

As $\theta$ varies (i.e. the short position is changed), $\mathrm{P}_{\mathrm{g}}$ will also vary, and using arguments similar to those found in section II

$$
\begin{aligned}
& P_{g \ell(\max )}=P_{g}\left[1-\left(r-r_{c}\right)^{2}\right], \\
& P_{g \ell(\min )}=P_{g}\left[1-\left(r+r_{c}\right)^{2}\right],
\end{aligned}
$$

where,

$$
\begin{gathered}
r=\frac{|a-b c|}{1-|c|^{2}}, \\
r_{c}=\frac{\left|b-a c^{*}\right|}{1-|c|^{2}} .
\end{gathered}
$$

By hypothesis, $\mathrm{P}_{\mathrm{g} \ell(\max )}$, and $\mathrm{P}_{\mathrm{g} \ell(\min )}$ may be measured by the vari-z power meter so (45) and (46) represent two equations in the (as yet) unknown quantities $\mathrm{P}_{\mathrm{g}}, \mathrm{r}, \mathrm{r}_{\mathrm{c}} \cdot$ To complete the determination, one more condition is required, moreover, if the procedure is to be independent of $\Gamma_{g}$, the condition must be a terminal invariant one. One candidate is the maximum efficiency, $\eta_{a}$, of the two-port associated with the vari-z power meter. It is given by [5], 


$$
n_{\mathrm{a}}=\frac{2 \mathrm{~T}}{1+\sqrt{1-4 \mathrm{~T}^{2}}},
$$

where,

$$
\mathrm{T}=\frac{\mid \mathrm{a}-\mathrm{bc|}}{1+|\mathrm{a}|^{2}-|\mathrm{b}|^{2}-|\mathrm{c}|^{2}} .
$$

With a little algebra, (50) becomes:

$$
T=\frac{r}{1+r^{2}-r_{c}^{2}} \text {. }
$$

Equation (49) may easily be inverted to obtain $\mathrm{T}$ in terms of $n_{a}$, and $n_{a}$ may be measured by the previously described techniques so (51) represents a relationship between $r$ and $r_{C}$. Equations (45), (46), (49), and (51) may be combined to yield:

$$
p_{g}=\frac{\frac{p q}{p+q}\left(1+2\left(\frac{1+n_{a}^{2}}{1-n_{a}^{2}}\right) \frac{\sqrt{p q}}{p+q}\right)}{1-\frac{\left(1+\eta_{a}^{2}\right)^{2}}{4 n_{a}^{2}}\left(\frac{p-q}{p+q}\right)^{2}},
$$

where $\mathrm{p}, \mathrm{q}$, represent $\mathrm{P}_{\mathrm{gl(max})}$ and $\mathrm{P}_{\mathrm{gl}(\mathrm{min})}$ respectively.

The measurement of $\mathrm{P}_{\mathrm{g}}$ may thus be effected by a variable impedance, terminating type power meter, in which the impedance variations are ultimately produced by a moving short. In use the device is connected to the generator of interest and the maximum and minimum values 
of net power in response to the short motion are observed. ${ }^{15}$ The maximum efficiency between the input port of the vari-Z power meter and the port where the moving short is connected must also have been determined. These values are then substituted in (52) to yield the desired result.

As previously noted, this scheme avoids the need for providing prescribed impedance values and is perhaps better suited for certain potential automation applications.

Although a detailed study has not been made, it would appear that the preferred value for $\eta_{a}$ would lie in the nominal range 0.1-0.8. In some cases the generator limitations on variations in load impedance will be the determining factor. If $n_{a}$ is large, the VSWR presented by the vari-z power meter will also be large and the extrapolation to more typical values of load impedance may suffer. On the other hand, if $n_{a}$ is small the power meter impedance will be nearly constant and the extrapolation again suffers.

These conclusions may also be inferred from (52) where it is noted that the last factor in the numerator contains the term $\left(1-n_{a}^{2}\right)^{-1}$, and the second term in the denominator contains the factor $n_{a}^{-2}$. With the help of (45), (46), (49), and (51), this latter term may be written,

${ }^{15}$ Although the most immediate use of this result is in the frequency regions where sliding shorts are practical, it may be possible to extend its application to lower frequencies by the use of adjustable reactances (eg. variable condensers, etc). Some study has also been given to a counterpart scheme using several fixed reactances; this approach appears promising but requires further investigation. 


$$
\frac{\left(1+n_{a}^{2}\right)^{2}(p-q)^{2}}{4 n_{a}^{2}(p+q)^{2}}=\frac{r_{c}^{2}\left(1+r^{2}-r_{c}^{2}\right)^{2}}{\left(1-r^{2}-r_{c}^{2}\right)^{2}} .
$$

From (49) and (51) it is evident that if $n_{a} \rightarrow 0, r \rightarrow 0$ and the right-hand-side in (53) approaches $r_{c}^{2}$ so the term does remain finite as $n_{a} \rightarrow 0$. As a practical matter, however, $n_{a}$ is more difficult to accurately measure when small, moreover the difference between $\mathrm{p}$ and $\mathrm{q}$ becomes small and difficult to determine.

The details for implementation of the vari-z power meter will be found in the next section.

V. IMPLEMENTATION OF THE VARI-Z POWER METER Although a major projected use for the vari-z power meter is in conjunction with measurements of $\mathrm{P}_{\mathrm{g}}$, other potential applications have been noted (section II). Moreover, the idea is not new [10]. The power equation concept, however, provides for a substantial expansion of the original idea.

It is convenient to begin with figure 3 and (20), which may be combined to yield:

$$
P_{g l}=K_{A} P_{4}\left(1-\frac{\left|w-R_{C}\right|^{2}}{R^{2}}\right) .
$$

Although the discussion and choice of terminology leading to this result have been built around an assumed excitation at port 1 , and a passive termination at port 2 , the focal 
point is port 2. No explicit reference is made to terminal 1 and the given result is also valid for excitation via port 2. To be more specific, (54) may also be used to determine the power $\underline{\text { input }}^{16}$ from a signal source connected to port 2 and an arbitrary termination (including a moving short) on port 1 .

Equation (54), however, is not in the most convenient form for this type of application since for certain terminations $\mathrm{P}_{4} \rightarrow 0, \mathrm{~W} \rightarrow \infty$, and the expression becomes indeterminate. With a little algebra (54) becomes:

$$
P_{g l}=\frac{-K_{A} P_{3}}{R^{2}-\left|R_{c}\right|^{2}}\left(1-\frac{\left|v^{*}+\frac{R_{c}^{*}}{R^{2}-\left|R_{c}\right|^{2}}\right|^{2}}{\left(\left.\frac{R^{2}}{R^{2}-\left|R_{c}\right|^{2}}\right|^{2}\right.}\right) \text {, }
$$

where $P_{3}=\left|b_{3}\right|^{2}$ and $v=\frac{b_{4}}{b_{3}}=\frac{1}{W}$. The similarity between (55) and (54) should be noted. Moreover, the minus sign may be deleted if it is understood that port 2 is now the input to a "termination" rather than the output of a "generator."

To extend this analogy it is convenient to define the parameter $\mathrm{K}_{\mathrm{T}}$,

$$
K_{T}=\frac{K_{A}}{R^{2}-\left|R_{c}\right|^{2}},
$$

$\overline{{ }^{16} \text { Note that "P }}$ " is now negative. 
and write, 17

$$
\mathrm{P}_{\mathrm{gl}}=\mathrm{K}_{\mathrm{T}} \mathrm{P}_{3} \mathrm{~L}_{\mathrm{cl}}
$$

where

$$
L_{C l}=1-\frac{\left|v+\frac{R_{C}^{*}}{R^{2}-\left|R_{C}\right|^{2}}\right|^{2}}{\left(\frac{R^{2}}{R^{2}-\left|R_{C}\right|^{2}}\right)^{2}} .
$$

Procedures for the measurement of $K_{A}, R$, and $R_{C}$ have been given in section II, these together with (56) may be used to determine $K_{T}$. It is usually preferable, however, to evaluate $\mathrm{K}_{\mathrm{T}}$ via an alternative procedure. Referring to (57), the device may be provided with a known power, Pgl, by use of the techniques for calibrating terminating type power meters described in section II. The evaluation of $L_{C l}$ assumes the knowledge of $R$, and $R_{C}$; this permits the determination of $\mathrm{K}_{\mathrm{T}}$.

The use of (55) presupposes a phase detection capability since the complex ratio $\frac{b_{4}}{b_{3}}$ is required. As before, this phase detection requirement may be eliminated by the introduction of tuning transformers. For example, as previously noted, the appropriate adjustment of a tuner inserted between the two couplers will cause $R_{c}$ to vanish. This case is the subject of reference [10].

${ }^{17}$ The minus sign has been dropped. 
In addition to satisfying the requirements for the measurement of $\mathrm{P}_{\mathrm{g}}$, there are other potential uses for the vari-z power meter. It has already been noted that there are field situations where the permanent installation of a directional coupler is untenable. Here the best solution to the measurement of $\mathrm{P}_{\mathrm{g} l}$ may be to terminate the vari-z power in such a way that its input impedance duplicates that of the load, for which it is then substituted, and $\mathrm{P}_{\mathrm{gl}}$ measured. Either of the foregoing arrangements (with or without tuning) are potentially applicable in this problem.

There is, in addition, another tuning adjustment which is of interest. For this application the order of the couplers should be reversed, and, indeed, for reasons which will emerge, this is generally desirable in the prior cases too.

The system is implemented as shown in figure 12. The merit of this arrangement lies in that $\mathrm{K}_{\mathrm{T}}$ is a property only of the coupler included between port 2 and $\mathrm{T}_{\mathrm{y}}$, and is indepedent of the adjustment of $\mathrm{T}_{y}$ or $\mathrm{T}_{z}$.

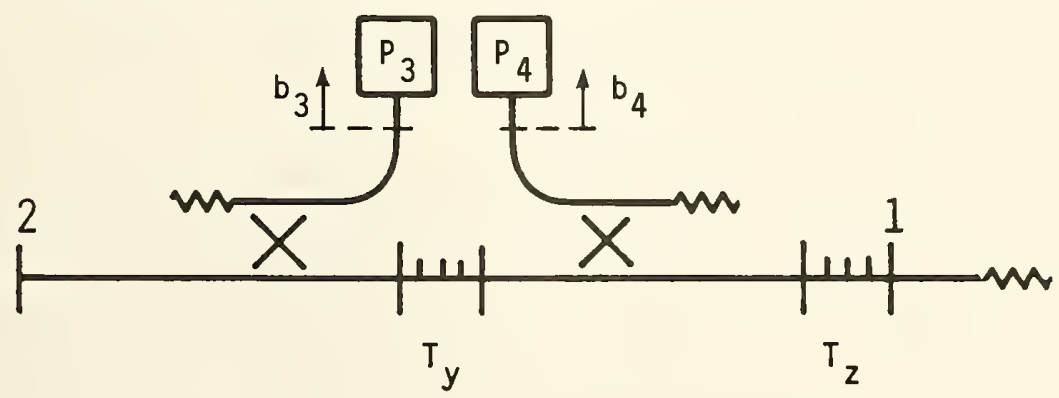

Figure 12. Alternative Form of Vari-Z Power Meter 
To demonstrate this point it is sufficient to recall that $\mathrm{K}_{\mathrm{A}}=\left[|\mathrm{D}|^{2}\left(1-\left|\Gamma_{\mathrm{g}}\right|^{2}\right)\right]^{-1}$ which may be combined with (7) to yie1d,

$$
\mathrm{K}_{\mathrm{A}}=\left(|\mathrm{D}|^{2}-|\mathrm{C}|^{2}\right\}^{-1}
$$

Equations (13), (14) may be combined to obtain,

$$
R^{2}-\left|R_{C}\right|^{2}=\frac{|A|^{2}-|B|^{2}}{|D|^{2}-|C|^{2}} \text {. }
$$

If these results are substituted into (56),

$$
K_{T}=\left(|A|^{2}-|B|^{2}\right\}^{-1} \text {. }
$$

Now by arguments similar to those employed in relation to $C$ and $D$ the parameters $A$ and $B$, (and thus $K_{T}$ ) depend only on that portion of the system "between" the detector which measures $\mathrm{P}_{3}$ and port 2 .

This arrangement is used as follows:

1. Excitation is applied via port 2 , port 1 is terminated by a load with nominal impedance match, and $\mathrm{T}_{z}$ adjusted so $\mathrm{b}_{4}=0$.

2. $\mathrm{T}_{\mathrm{y}}$ is adjusted to yield the required input imped ance .

3. Port 2 of the system is connected to the generator for which $\mathrm{P}_{\mathrm{gl}}$ is required and $\mathrm{P}_{3}$ noted.

4. The system is next excited via port 1 , a sliding short is connected to port $2,\left|\frac{b_{3}}{b_{4}}\right|_{\max }$ and $\left|\frac{b_{3}}{b_{4}}\right|_{\min }$ are observed. 
5. Using (16) and (17), $R$ and $\left|R_{C}\right|$ may be determined. This leads to:

$$
P_{g l}=K_{T} P_{3}\left(1-\left(\frac{\left|\frac{b_{3}}{b_{4}}\right|_{\max }-\left|\frac{b_{3}}{b_{4}}\right|_{\min }}{\left|\frac{b_{3}}{b_{4}}\right|_{\max }+\left|\frac{b_{3}}{b_{4}}\right|_{\min }}\right)^{2}\right) \text {. }
$$

(Note that this assumes $\mathrm{K}_{\mathrm{T}}$ has also been measured.)

As compared with the previously described technique [10], the tuning adjustments are more easily realized, but $R$ and $\left|R_{c}\right|$ have to be remeasured every time the device is adjusted for a new value of input impedance. This is avoided in the previous case but the required adjustment is more difficult to realize.

Comparing figures 12 , and 3 , also (23), (57) it is noted that in one case the measurement of "P 4 " plays a major role, in the other case the measurement of " $\mathrm{P}_{3}$. " The choice of terminology is, of course, arbitrary. This particular convention is the result of showing how (55) could be obtained by use of (54). It will prove instructive to assume that the coupler which yields "b 3 " is in reality that previously used to obtain "b 4 ." The arrangement shown in figure 2 thus provides the "key" element in both applications. Now since $\mathrm{K}_{\mathrm{A}}, \mathrm{K}_{\mathrm{T}}$ are associated with the same coupler it is of interest to note (see Appendix IV) they are related by the equation,

$$
\mathrm{K}_{\mathrm{A}}=\left.\mathrm{K}_{\mathrm{T}^{\mathrm{n}} 12}\right|_{\mathrm{P}_{4}=0} \text {, }
$$


where $n_{12}$ is the "efficiency" of the coupler in figure 2 for an assumed power flow from port 2 to port 1 , where the latter has been terminated in such a way that $\mathrm{P}_{4}=0$. This efficiency may be measured as previously described (29), and provides another method of obtaining $\mathrm{K}_{\mathrm{T}}$ when $\mathrm{K}_{\mathrm{A}}$ is known, or conversely.

VI. IMPLEMENTATION OF A VARI-Z POWER METER BY A SINGLE COUPLER The previously described implementations have required a pair of directional couplers and associated power detectors. It is also possible to satisfy the requirements for the measurement of $\mathrm{P}_{\mathrm{g}}$ by a single coupler arrangement, although the vari-z power meter, thus obtained, does not have the additional applications noted in the previous section. Moreover it is not possible, generally speaking, to avoid the tuning requirement in the single coupler arrangement.

Referring to figure 13 , it is convenient to begin with an arbitrary three port junction, where port 1 is the (vari-Z) power meter input, port 2 is terminated by a power meter, and port 3 is connected to a moving short. In order to satisfy the requirements of section $I V$, it is required that the efficiency between ports 2 and 1 be independent of the short position. By use of the arguments found in [10], there is no loss in generality in assuming that the power meter which terminates port 2 is reflectionless. The efficiency of the 
two-port, $\eta_{21}$ may then be written ${ }^{18}$

$$
n_{21}=\frac{\left|S_{21}+\frac{S_{23} S_{31} e^{i \theta}}{1-S_{33} e^{i \theta}}\right|^{2}}{1-\left|S_{11}+\frac{S_{13} S_{31} e^{i \theta}}{1-S_{33} e^{i \theta}}\right|^{2}},
$$

where the $S_{m n}$ are the scattering coefficients of the 3-port, and $\theta$ is a function of the short position. The next step is to ask under what condition $\eta_{21}$ will be independent of the choice of $\theta$. Although it is possible to give a condition which is both necessary and sufficient, the discussion of this general case is tedious. Instead a number of special cases will be considered and the nature of the general solution briefly described.

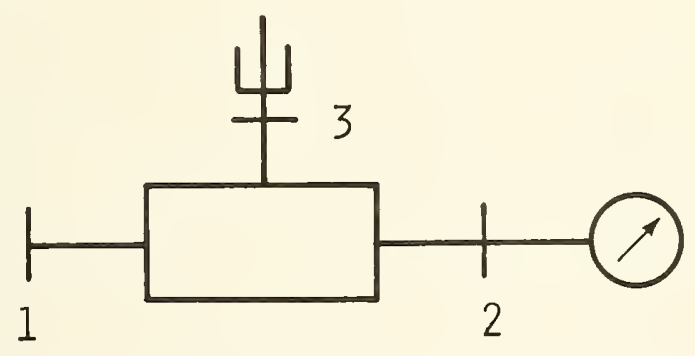

Figure 13. Use of 3-port as a Vari-z Power Meter

${ }^{18}$ In terms of scattering parameters, the efficiency of a two port terminated in a matched load is given by $n=$ $\left|S_{21}\right|^{2} /\left(1-\left|S_{11}\right|^{2}\right)$. To generalize this result for a three port, one arm of which is terminated in a moving short, one sets $a_{3}=b_{3} e^{i \theta}$. The three-port scattering equations then reduce to two-port form, from which the scattering parameters of the resultant "two-port" may be determined by inspection and substituted in the above equation. 
From (64) a sufficient condition that $\eta_{21}$ be independent of $\theta$ is for $S_{11}, S_{33}$ and either $S_{21}$ or $S_{23}$ to vanish. In figure 14 is shown four possible arrangements, built around a directional coupler and tuning transformers, by which these criteria may be realized. To obtain this adjustment in figure $14 \mathrm{a}$ or $14 \mathrm{~b}$, the junction is first excited via port 3 , and port 1 terminated by a matched (reflectionless) termination. Transformer $\mathrm{T}_{1}$ is now adjusted for no signal at port 2 $\left(\mathrm{S}_{23}=0\right)$ and $\mathrm{T}_{3}$ adjusted for a match (reflectionless) looking into port $3\left(\mathrm{~S}_{33}=0\right)$. Excitation is now applied at port 1 , port 3 is terminated in a matched load, and $\mathrm{T}_{2}$ adjusted for a match looking into port $1\left(\mathrm{~S}_{11}=0\right)$. The above criteria are now satisfied.

The procedure for adjusting the configurations of figure $14 \mathrm{c}$ and $14 \mathrm{~d}$ is similar. With excitation applied at port 1 , and a matched termination at port $3, \mathrm{~T}_{3}$ is adjusted for a null at port $2\left(\mathrm{~S}_{21}=0\right)$ and $\mathrm{T}_{1}$ adjusted for a match at port $1\left(\mathrm{~S}_{11}=0\right)$. Excitation is next applied at port 3, the matched termination is connected to port 1 , and $\mathrm{T}_{2}$ adjusted for a match at port $3\left(S_{33}=0\right)$. The above criteria are again satisfied.

Although the foregoing adjustments are sufficient to yield the desired behavior, they fall outside the power equation philosophy. However it is easily recognized that tuners $\mathrm{T}_{1}, \mathrm{~T}_{3}$ are unnecessary except as a means of recognizing 

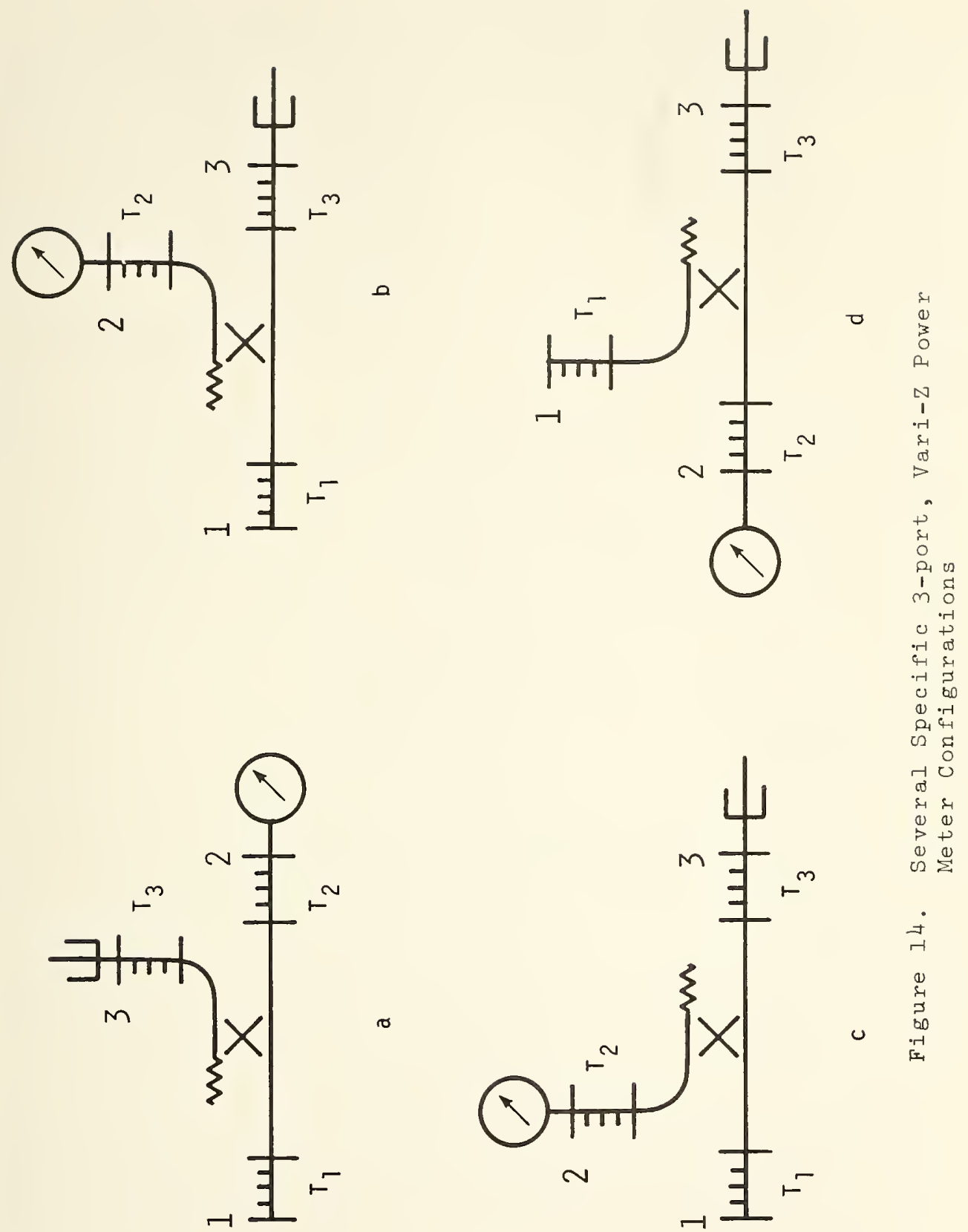
the proper adjustment of $\mathrm{T}_{2}$. The basis for this observation is the "terminal invariant" character of the subsequent operations at terminals 1 and 3 . In particular, terminal 3 is terminated by a moving short (whose phase is not required), while only the net power is of interest at terminal 1 . This indicates that it should be possible to satisfy the basic requirements by an adjustment of $\mathrm{T}_{2}$ alone.

By means of techniques described in section II, it is possible to construct a feed-through meter which reads net power. With port 1 (figure 14) connected to the output of such a device, it should be possible to adjust $\mathrm{T}_{2}$ for a constant ratio of indicated to delivered power for all short positions. A more detailed discussion is outside the scope of this paper.

VII. MEASUREMENT OF SMALL VALUES OF $n_{\mathrm{a}}$ As previously noted, the methods for measuring $n_{a}$, described in section III, becomes impractical as the value of $n_{a}$ becomes small (typically 0.1 and less), or if reciprocity is not satisfied. As a consequence, other procedures must be devised. The previously described solutions [3], [5] to this problem called for tuning. This is now to be eliminated. By use of the foregoing methods, a variety of techniques may be devised. 
The basic setup is shown in figure 15. The "power meter" which terminates port 1 may assume a variety of forms, including (but not limited to) the vari-Z arrangement.

By the use of $(25),(27)$, the power output, $P_{g_{l_{1}}}$, from the two-port under test, may be written

$$
\mathrm{P}_{\mathrm{g} \ell_{1}}=\mathrm{P}_{\mathrm{g}} \mathrm{gan}_{\mathrm{g}} \mathrm{a}^{\mathrm{N}} \mathrm{al}
$$

or alternatively, by use of (26), (28),

$$
\mathrm{P}_{g \ell_{1}}=\mathrm{P}_{\mathrm{g}} \mathrm{Nga}_{\mathrm{g}} \mathrm{M}_{\mathrm{al}} \text {. }
$$

With the two-port removed, the power output, $\mathrm{P}_{\mathrm{g}_{2}}$ becomes,

$$
\mathrm{P}_{\mathrm{g} \ell_{2}}=\mathrm{P}_{\mathrm{g}} \mathrm{M}_{\mathrm{g} l} \text {. }
$$

Assuming $\mathrm{P}_{\mathrm{g}}$ is held constant, equations (66) and (67) now yield,

$$
\frac{\mathrm{P}_{\mathrm{g} \ell_{1}}}{\mathrm{P}_{\mathrm{g} \ell_{2}}}=\frac{\mathrm{N}_{\mathrm{ga}} \mathrm{a}^{\mathrm{M}} \mathrm{al}}{\mathrm{M}_{\mathrm{gl}}},
$$

and this provides a determination of $n_{a}$ provided that the mismatch factors and the ratio $\mathrm{P}_{\mathrm{gl}_{1}} / \mathrm{P}_{\mathrm{g} \ell_{2}}$ are measured. The measurement of $\mathrm{P}_{\mathrm{g} \ell}$ and $\mathrm{M}_{\mathrm{a} \ell}$ is perhaps most conveniently obtained by the arrangement of figure 6 . The terms $\mathrm{N}_{\mathrm{ga}}$ and $\mathrm{M}_{\mathrm{g} \ell}$ are then obtained as described in section III. Alternatively, a similar expression results if (67) is combined with (65). Instead of $\mathrm{N}_{\mathrm{ga}}, \mathrm{M}_{\mathrm{al}}$, it is necessary to measure $\mathrm{M}_{\mathrm{ga}}, \mathrm{N}_{\mathrm{al}}$. Although the prior discussion has centered around its use in measurement of the " $M$ " type of mismatch, the arrangement of figure 6 may also be used to determine $\mathrm{N}_{\mathrm{a} \ell}$. 


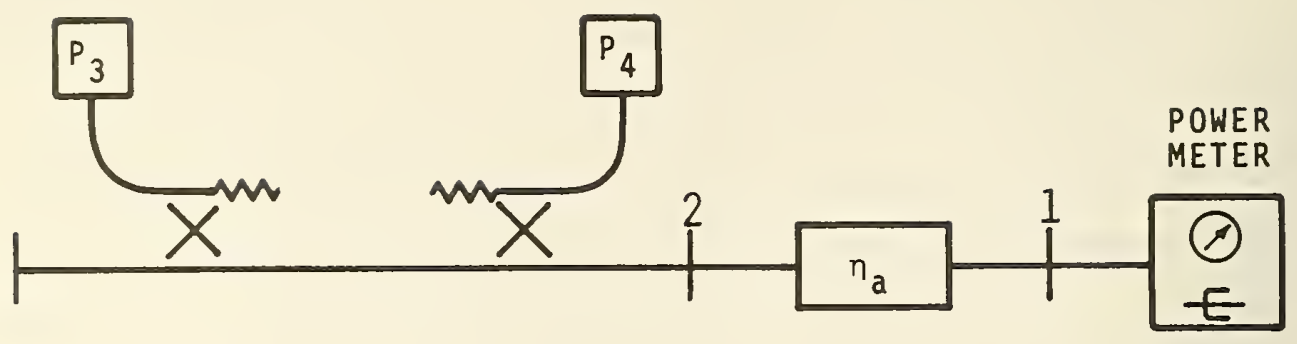

Figure 15. Circuit for Measuring Small Values of $\eta_{a}$

The foregoing methods have the disadvantage that a signal source is required in conjunction with the terminating "power meter." The need for this signal source may be eliminated by use of one of the schemes for measuring available power described in sections IV, V, VI. Referring to (66) and figure 15 the available power, $P_{g_{1}}$, at terminal 1 is given by

$$
\mathrm{P}_{\mathrm{g}_{1}}=\mathrm{P}_{\mathrm{g}} \mathrm{N}_{\mathrm{ga}} \mathrm{n} \text {, }
$$

while that at terminal $2, \mathrm{P}_{\mathrm{g}_{2}}$, is just,

$$
\mathrm{P}_{\mathrm{g}_{2}}=\mathrm{P}_{\mathrm{g}} \text {. }
$$

Assuming $\mathrm{P}_{\mathrm{g}_{1}}, \mathrm{P}_{\mathrm{g}_{2}}$, and $\mathrm{N}_{\mathrm{ga}}$ are measured, $\mathrm{n}_{\mathrm{a}}$ may be determined from (69), (70).

\section{SUMMARY}

This paper has presented the theoretical basis for a wide collection of measurement techniques which satisfy the constraints of the power equation concept. In making this collection the emphasis has been on completeness, and little or no 
attempt has been made to assess the practical merit of the many alternatives. Although a number of these ideas, particularly those described in Section II have already demonstrated their merit, there are others whose validity or practical value awaits experimental confirmation.

The rationale adopted in this paper differs from prior descriptions in that, for the most part, a phase detection capability is assumed. Although this represents a substantial increase in the complexity of the associated equipment, this feature also permits the elimination of the tuning transformer and leads to procedures which are compatable with today's automated systems.

The assumed phase detection capability has also made it possible to present the theory in a concise form in which the phase detection requirements are explicitly displayed. This also permits one to recognize by inspection the many and varied alternatives for the use of tuning to eliminate the phase measurement requirement. Such methods come out of the general theory as special cases, and are of value in those cases where the investment in instrumentation must be kept to a low level.

With the exception of recent work on a six-port [11] and a specific procedure for implementing Kerns' impedance method of evaluating bolometer mount efficiency [12], this paper 
represents a fairly complete catalogue of the measurement methods for implementing the power equation concept as they exist at this writing.

\section{IX . ACKNOWLEDGMENT}

As noted earlier, this work is in response to a growing interest in the power equation concept. In particular the author has been stimulated by the efforts of Fred R. Hume, Autonetics Division, North American Rockwe1l, and R.D. Moyer, Sandia Laboratories, who are actively reducing these concepts to practical measurement practice. In addition, some of the theoretical results, contained herein, have been independently derived by Mr. Moyer in an alternative form [2]. The author also expresses his appreciation to Mr. C.A. Hoer, and Mr. Moyer for their constructive suggestions in the preparation of this manuscript .

This effort was sponsored by the DoD Calibration Coordination Group. 


\section{REFERENCES}

[1] Hume, F.R., Koide, F.K., and Dederich, D.J., Practical and Precise Means of Microwave Power Meter Calibration Transfer, IEEE Trans. on Instr. and Meas., IM-21, No. 4, 457-466, (Nov. 1972).

[2] Moyer, R.D., Terminal Invariant Parameter Determinations from Complex Signal Ratio Measurements, IEEE Trans. on Instr. and Meas., IM-21, No. 4, 532-537, (Nov. 1972).

[3] Engen, G.F., Power Equations: A New Concept in the Description and Evaluation of Microwave Systems, IEEE Trans. on Instr. and Meas. IM-20, No. 1, 49-57, (Feb. 1971).

[4] Engen, G.F., and Beatty, R.W., Microwave Reflectometer Techniques, IRE Trans. Microwave Theory and Tech., MTT-7, 351-355, (July 1959) .

[5] Engen, G.F., An Introduction to the Description and Evaluation of Microwave Systems Using Terminal Invariant Parameters, NBS Monograph 112, (Oct. 1969).

[6] Engen, G.F., Amplitude Stabilization of a Microwave Signal Source, IRE Trans. on Microwave Theory and Tech., MTT-6, No. 2, 202-206, (April 1958).

[7] Engen, G.F., A Method of Determining the Mismatch Correction in Microwave Power Measurements, IEEE Trans. Instr. and Meas., IM-17, No. 4, 392-395, (Dec. 1968).

[8] Miller, C.K.S., Daywitt, W.C., and Arthur, M.G., Noise Standards, Measurements, and Receiver Noise Definitions, Proc. IEEE, 55, No. 6, 865-877, (June 1967). 
[9] Bowman, R.R., Field Strength Above I GHz: Measurement Procedures for Standard Antennas, Proc. IEEE, 55, No. 6, 981-990, (June 1967).

[10] Engen, G.F., 4 Variable Impedance Power Meter and Adjustable Reflection Coefficient Standard, J. Research, NBS, 68C, 7-24, (Jan.-Mar. 1964).

[11] Engen, G.F., and Hoer, C.A., Application of an Arbitrary 6-port Junction to Power Measurement Problems, IEEE Trans. on Instr. and Meas., IM-21, No. 4, 470-474, (Nov. 1972).

[12] Engen, G.F., A Bolometer Mount Efficiency Measurement Technique, J. Research, NBS, 65C, 113-124, (April-June 1961). 


\section{APPENDIX I}

In the earlier discussion of figure 6 , certain sources of error were noted which will now be considered in greater detail. This is perhaps most conveniently done in terms of a specific example.

By use of the arguments contained in [6], it is possible to replace the "second" directional coupler and source by a simple generator, of reflection coefficient $\Gamma_{S}$ as shown in figure 16. In addition, the tuner $\left(\mathrm{T}_{\mathrm{y}}\right)$ and load of figure 6 have been replaced by an adjustable termination $\Gamma_{t}$. A $20 \mathrm{~dB}$ value will be assumed for both coupling ratio and directivity. Finally, the magnitudes of the reflection coefficients are assumed to be typically 0.2 (VSWR $=1.5$ ) or less. Following the measurement of $\mathrm{M}_{\mathrm{gl}}$, as explained in Section II, the generator on arm 1 is "turned off" or replaced by a passive termination of the same impedance.

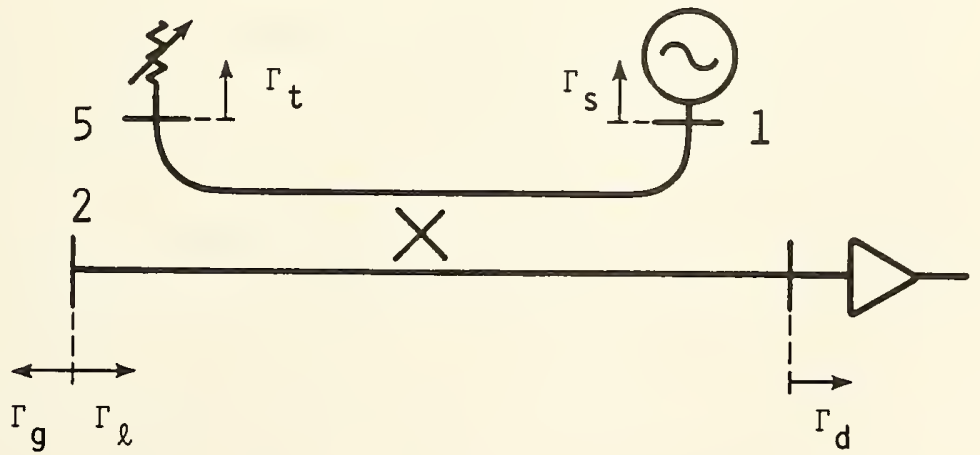

Figure 16. Circuit for Further Discussion of "Alternate" $\mathrm{M}_{\mathrm{gl}}$ Application 
Two questions must now be answered:

1) What change in $M_{g l}$ is engendered by failure of the passive load impedances to duplicate the active one?

2) How does the power transmission efficiency from terminal 2 to terminal 3 depend upon $\Gamma_{s}$ and $\Gamma_{t}$ ?

With regard to the first question it should be noted that whereas $\Gamma_{\ell}$ has a (small) dependence upon $\Gamma_{t}$, this is automatically taken care of since the cited procedure measures $\mathrm{M}_{\mathrm{g} \text { l }}$ for what ever value of $\Gamma_{\ell}$ results when the adjustment of $\Gamma_{t}$ is completed. Let $\Gamma_{S}$ and $\Gamma_{S}^{\prime}$ refer to the active and passive terminations respectively, and let $\Gamma_{\ell}, \Gamma_{\ell}^{\prime}$ represent the corresponding values at terminal 2. Then, if only the first order terms are retained,

$$
\Gamma_{\ell}^{\prime}-\Gamma_{\ell} \simeq S_{12} S_{21}\left(\Gamma_{s}^{\prime}-\Gamma_{s}\right)
$$

and for the assumed $20 \mathrm{db}$ coupling factor,

$$
\left|\Gamma_{\ell}^{\prime}-\Gamma_{\ell}\right| \simeq\left|\Gamma_{S}^{\prime}-\Gamma_{S}\right| \times 10^{-2}
$$

To continue the discussion, a value of 0.2 is assumed for $\left|\Gamma_{s}^{\prime}-\Gamma_{s}\right|$. (This means, for example, if the generator on arm 1 is reflectionless, the passive termination which replaces it may have a VSWR as large as 1.5 and conversely.) Finally, the values of $\left|\Gamma_{\ell}\right|$ and $\left|\Gamma_{g}\right|$ are also assumed to be 0.2 .

If, now, these values are substituted in (9), and the worst phase conditions are assumed, this leads to an error of $0.16 \%$ in $\mathrm{M}_{\mathrm{gl}}$. Except for the most careful work, this error 
is ordinarily negligible. Moreover, it can obviously be reduced by ensuring that $\Gamma_{S}^{\prime}$ is more nearly equal to $\Gamma_{S}$. This example demonstrates that even a "token" effort in this area is adequate for most practical purposes.

With regard to the second question, the power transmission efficiency is determined primarily by $\left|\mathrm{S}_{32}\right|^{2}$. As before a prime will be used to differentiate between initial and final values, and only the first order terms will be retained. Then

$$
\begin{aligned}
S_{23}^{\prime}-S_{23} \simeq S_{52} S_{55}\left(\Gamma_{t}^{\prime}-\Gamma_{t}\right) & +S_{12} S_{31}\left(\Gamma_{s}^{\prime}-\Gamma_{s}\right) \\
& +S_{12} S_{51} S_{35}\left(\Gamma_{s}^{\prime} \Gamma_{t}^{\prime}-\Gamma_{s} \Gamma_{t}\right)
\end{aligned}
$$

Again values of 0.2 will be assumed for $\left|\Gamma_{s}^{\prime}-\Gamma_{s}\right|,\left|\Gamma_{t}^{\prime}-\Gamma_{t}\right|$, and as an upper limit for the values $\left|\Gamma_{s}^{\prime}\right|,\left|\Gamma_{s}\right|,\left|\Gamma_{t}^{\prime}\right|,\left|\Gamma_{t}\right|$. For the assumed directivity and coupling values, $\left|\mathrm{S}_{52} \mathrm{~S}_{35}\right|$ and $\left|\mathrm{S}_{12} \mathrm{~S}_{31}\right|$ are nominally $10^{-3}$ while $\left|\mathrm{S}_{12} \mathrm{~S}_{51} \mathrm{~S}_{35}\right| \simeq 10^{-2}$. The last term in (A-3) is thus the important one, and for the assumed conditions may be as large as .0008 . This, in turn, may change the power transmissions efficiency by as much as $0.16 \%$.

As before, this error may be reduced by making $\Gamma_{S}^{\prime}$ more nearly equal to $\Gamma_{S}$. The value of $\Gamma_{t}^{\prime}$, however is dictated by the value of $\Gamma_{g}$ and less subject to user control, at least without restricting the range of potential application. On the other hand, the sensitivity to the $\left|\Gamma_{t}^{\prime}-\Gamma_{t}\right|$ term may be reduced by the proper choice of $\Gamma_{S}$. If $\Gamma_{S}^{\prime}=\Gamma_{S},(A-3)$ becomes, 


$$
S_{23}^{\prime}-S_{23} \simeq\left(S_{52} S_{35}+S_{12} S_{51} S_{35} \Gamma_{S}\right)\left(\Gamma_{t}^{\prime}-\Gamma_{t}\right)
$$

and the right hand side vanishes for the proper choice of $\Gamma_{\mathbf{S}}$. In practice the correct adjustment of $\Gamma_{s}$ may be recognized by exciting the system via port 2 , and adjusting $\Gamma_{S}$ for a null in arm 5 .

The foregoing example demonstrates that the assumed $20 \mathrm{~dB}$ coupling and directivity are ordinarily sufficient to insure negligable errors except in the most exacting applications. Moreover, this error may be reduced by the cited measures or by increasing the coupling and directivity values. 
The purpose of this appendix is to find the maximum value of $\eta_{a l}$, as given by (31), as a function of $w$. Conceptually, this is a straightforward exercise in differential calculus, however the effort involved may be substantial unless certain "short-cuts" are observed.

As it stands, (31) is not an analytic function of $\mathrm{w}$ because of the absolute value operation. However if $x$ and $y$ represent the real and imaginary parts of $w$, it is convenient to consider $w$ and $w^{*}$ as two different functions of the independent variables $x, y$. Equation (31) can then be written as an analytic function of $\mathrm{w}$ and $\mathrm{w}^{*}$,

$$
\eta_{a l}=\frac{R_{2}}{R_{1}} \frac{\left(R_{1}^{2}-\left(w-R_{c_{1}}\right)\left(w^{*}-R_{c_{1}}^{*}\right)\right.}{\left(R_{2}^{2}-\left(w-R_{c_{2}}\right)\left(w^{*}-R_{c_{2}}^{*}\right)\right\}} .
$$

A necessary and sufficient condition (see Appendix 3) that $\eta_{a l}$ have an extremum is for

$$
\frac{\partial \eta \mathrm{a} \ell}{\partial w}=0,
$$

(and in which $\mathrm{w}^{*}$ is assumed to be a constant).

Together with $(A-5)$ this leads to,

$$
\frac{R_{1}^{2}-\left|w-R_{c_{1}}\right|^{2}}{R_{2}^{2}-\left|w-R_{c_{2}}\right|^{2}}=\frac{w-R_{c_{1}}}{w-R_{c_{2}}}
$$

as the condition on $w$ for which $\eta_{a}$ is a maximum $\left(\eta_{a}\right)$. 
It is thus permissible to substitute $\eta_{a}$ for $\eta_{a l}$ in (A-5), provided that $w$ satisfies $(A-7)$. The remaining step is to eliminate $w$ between $(A-5)$ and $(A-7)$. In theory, (A-7) would be solved for $w$ and substituted in (A-5) but this approach is tedious. Comparison of $(A-5)$ and $(A-7)$ shows that,

$$
\eta_{a}=\frac{R_{2}}{R_{1}} \frac{\left(w-R_{c_{1}}\right)}{\left(w-R_{c_{2}}\right)} \text {. }
$$

After cross multiplication and cancellation, (A-7) may be written,

$$
\frac{W-R_{C_{1}}}{W-R_{c_{2}}}=\frac{R_{1}^{2}+\left(W-R_{C_{1}} j\left(R_{C_{1}}^{*}-R_{C_{2}}^{*}\right)\right.}{R_{2}^{2}}
$$

And this may be combined with (A-8) to obtain,

$$
n_{a}=\frac{R_{1}^{2}+\left(w-R_{C_{1}}\right)\left(R_{C_{1}}^{*}-R_{C_{2}}^{*}\right)}{R_{1} R_{2}}
$$

At this point (A-8) is solved for $w$, and substituted in $(A-9)$. This leads to (32). 


\section{APPENDIX III}

Given an analytic function $p$, of the complex variables $z, z^{*}$ such that $p$ is real for all choices of $z$, it will be shown that a necessary and sufficient condition for an extremum of $\mathrm{p}$ is that,

$$
\frac{\partial p}{\partial z}=0 \text {. }
$$

It will prove convenient to introduce some additional notation :

$$
\begin{aligned}
z & =u=x+j y \\
z^{*} & =v=x-j y
\end{aligned}
$$

where $x$ and $y$ are respectively the real and imaginary components of $z$.

Then,

$$
p=f(u, v)
$$

and following the usual rules for differentiation,

$$
\begin{aligned}
d p= & \frac{\partial f}{\partial u} d u+\frac{\partial f}{\partial v} d v \\
& \frac{\partial f}{\partial u}(d x+j d y)+\frac{\partial f}{\partial v}(d x-j d y) \\
= & \left(\frac{\partial f}{\partial u}+\frac{\partial f}{\partial v}\right) d x+j\left(\frac{\partial f}{\partial u}-\frac{\partial f}{\partial v}\right) d y
\end{aligned}
$$

To further simplify the notation, let $\frac{\partial f}{\partial u}=\alpha, \frac{\partial f}{\partial v}=\beta$. Then $(A-14)$ becomes,

$$
d p=(\alpha+\beta) d x+j(\alpha-\beta) d y
$$


By hypothesis, $\mathrm{p}$ is real for all choices of $\mathrm{x}$ and $\mathrm{y}$. Therefore $d p$ must be real for arbitrary $d x$, dy. This is only possible if $(\alpha+\beta)$ is a real number, and $(\alpha-\beta)$ is imaginary. This leads to the following equations,

from which,

$$
\begin{aligned}
& \alpha+\beta=\alpha^{*}+\beta^{*}, \\
& \alpha-\beta=-\alpha^{*}+\beta^{*},
\end{aligned}
$$

$$
\alpha=\beta^{*} \text {. }
$$

From (A-18), if a vanishes, the same is true of $\beta$, and (A-15) shows this is sufficient to ensure $d p=0$. Conversely, it is easily recognized from (A-15) that if dp vanishes for arbitrary $\mathrm{dx}$, dy, this requires $\alpha=\beta=0$. This completes the proof. 


\section{APPENDIX IV}

This appendix will outline derivation of (63). As noted in the discussion attending (63), it is instructive to let the circuit of figure 2 represent alternatively the "output" element of figure 3 and the "input" element of figure 12. In the former case, no change in terminology is required, but in the latter, the "P 3 " and "port 2" of figure 12, become the "P 4 " and "port 1" of figure 2 respectively. As previously noted, the parameters C, D are determined by the "output" coupler of figure 3, while A, B are parameters of the "input" coupler of figure 12 .

In figure 2 , as previously noted,

$$
\mathrm{b}_{4}=\mathrm{Ca}_{2}+\mathrm{Db}_{2}
$$

while the change in terminology outlined above leads to

$$
\mathrm{b}_{4}=\mathrm{Aa}_{1}+\mathrm{Bb}_{1} \text {. }
$$

It will now prove convenient to consider the scattering description ${ }^{18}$ of figure 2 .

$$
\begin{aligned}
& \mathrm{b}_{1}=\mathrm{s}_{11} \mathrm{a}_{1}+\mathrm{s}_{12} \mathrm{a}_{2} \\
& \mathrm{~b}_{2}=\mathrm{s}_{12} \mathrm{a}_{1}+\mathrm{s}_{22} \mathrm{a}_{2} \\
& \mathrm{~b}_{4}=\mathrm{s}_{41} \mathrm{a}_{1}+\mathrm{s}_{42} \mathrm{a}_{2}
\end{aligned}
$$

where reciprocity $\left(\mathrm{S}_{12}=\mathrm{S}_{21}\right)$ has been assumed. This system of equations (A-21) can be solved for $\mathrm{b}_{4}$ as a linear function of any two of the parameters $a_{1} a_{2}, b_{1}, b_{2}$. Equations (A-19),

${ }^{18}$ By use of the arguments contained in [10] it is permissible to assume $\mathrm{a}_{4}=0$. 
(A-20) are two such equations. ${ }^{19}$ In addition,

$$
b_{4}=\frac{S_{21}}{S_{11}}\left(D b_{1}-A a_{2}\right) .
$$

The efficiency, $n_{12}$, is given by,

$$
n_{12}=\frac{\left|b_{1}\right|^{2}-\left|a_{1}\right|^{2}}{\left|a_{2}\right|^{2}-\left|b_{2}\right|^{2}}
$$

subject to the condition, $\mathrm{b}_{4}=0$. This condition, in combination with, $(A-19),(A-20),(A-22),(A-23)$ leads to,

$$
\left.n_{12}\right|_{\mathrm{P}_{4}=0}=\frac{|\mathrm{A}|^{2}-|\mathrm{B}|^{2}}{|\mathrm{D}|^{2}-|\mathrm{C}|^{2}} \text {. }
$$

Finally, this result may be compared with (59) and (61) to obtain (63).

${ }^{19}$ Explicit expressions for $A \cdots D$ in terms of the $S_{m n}$ could be introduced but these are not required. 


\section{APPENDIX V}

Throughout this paper it has been assumed that the described systems are such that $R>\left|R_{C}\right|$. Returning to (13) and (14), this will be true if,

$$
\left|\frac{A D-B C}{|D|^{2}-|C|^{2}}\right|>\left|\frac{B D^{*}-A C^{*}}{|D|^{2}-|C|^{2}}\right|
$$

Squaring both sides and cancellation yields,

$$
|A D|^{2}+|B C|^{2}>|B D|^{2}+|A C|^{2} \text {. }
$$

This may be simplified to obtain,

$$
\left(|A|^{2}-|B|^{2}\right)\left(|D|^{2}-|C|^{2}\right)>0 \text {, }
$$

So that $R>\left|R_{C}\right|$ provided that

$$
\begin{aligned}
& |\mathrm{A}|>|\mathrm{B}|, \\
& |\mathrm{D}|>|\mathrm{C}| .
\end{aligned}
$$

In terms of (3) and (10), this means that $b_{4}$ must be more strongly coupled to $b_{2}$ than to $a_{2}$, while the converse must be true of $b_{3}$. Alternatively, one may have $|B|>|A|$ and $|C|>|D|$, but this is of no interest in the immediate context. 
FORM NBS-114A $(1.71)$

\begin{tabular}{|c|c|c|c|}
\hline $\begin{array}{l}\text { U.S. DEPT. OF COMM. } \\
\text { BIBLIOGRAPHIC DATA } \\
\text { SHEET }\end{array}$ & $\begin{array}{l}\text { 1. PUBLICATION OR REPORT NO. } \\
\text { iv BS TN }-637\end{array}$ & $\begin{array}{l}\text { 2. Goo't Accession } \\
\text { No. }\end{array}$ & 3. Recipient's Accession No. \\
\hline \multicolumn{3}{|c|}{$\begin{array}{l}\text { 4. TITLE AND SUBTITLE } \\
\text { Theory of UHF and Microwave Measurements Using the Power } \\
\text { Equation Concept }\end{array}$} & \begin{tabular}{|l|} 
5. Publication Date \\
April 1973 \\
6. Perforning Organization Code
\end{tabular} \\
\hline \multicolumn{3}{|l|}{$\begin{array}{l}\text { 7. AUTHOR(s) } \\
\text { Glenn F. Engen }\end{array}$} & 8. Performing Organization \\
\hline \multicolumn{3}{|c|}{$\begin{array}{l}\text { NATIONAL BUREAU OF STAND ARDS, Boulder Labs. } \\
\text { DEPARTMENT OF COMMERE } \\
\text { Boulder, Colorado } 80302\end{array}$} & $\begin{array}{l}\text { 10. Project/Task/Work Unit No. } \\
2721393 \\
11 . \text { Contract/Grant No. } \\
\text { CCG Project }\end{array}$ \\
\hline \multicolumn{3}{|c|}{$\begin{array}{l}\text { 12. Sponsoring Organization Name and Address } \\
\text { Calibration Coordination Group } \\
\text { Department of Defense }\end{array}$} & $\begin{array}{l}\text { 13. Type of Report \& Period } \\
\text { Covered } \\
\text { Final } \\
\text { 14. Sponsoring Apency Code }\end{array}$ \\
\hline
\end{tabular}

15. SUPPLEMENTARY NOTES

16. ABSTRACT (A 200-word or less factual summary of most significant information. If document includes a significant bibliography or literature survey, mention it here.)

Theoretical considerations indicate that, in addition to other advantages, UHF and microwave measurements based on the power equation concept should exhibit reduced sensitivity to certain connector imperfections. This has now been experimentally confirmed in a number of laboratories, and interest in these methods is increasing. The previously described measurement techniques, for implementing this concept, have relied heavily upon tuning procedures, while current trends are towards automation where tuning is impractical if not impossible.

By assuming a phase detection capability (such as is found in automated systems) it is possible to eliminate the tuning requirement. Moreover, this generalization has made it possible to summarize the earlier results in a compact form. In addition, this paper includes a number of new measurement ideas.

It is expected that this report will serve as a major reference in the continuing development of detailed measurement procedures which exploit the power equation concept.

17. KEY WORDS (Alphabetical order, separated by semicolons)

Microwave; Microwave measurements; Power equation; Power measurement; Terminal

invariant.

\section{AVAILABILITY STATEMENT}

UNLIMIT ED.

FOR OFFICI AL DIST RIBUTION. DO NOT RELEASE TO NTIS.

\begin{tabular}{|l|c|}
\hline $\begin{array}{c}\text { 19. SECURITY CLASS } \\
\text { (THIS REPORT) }\end{array}$ & 21. NO. OF PAGES \\
UNCL ASSIFIED & 68 \\
\hline $\begin{array}{l}\text { 20. SECUR ITY CLASS } \\
\text { (THIS PAGE) } \\
\text { UNCL ASSIFIED }\end{array}$ & 22. Price \\
\hline
\end{tabular}




\section{PERIODICALS}

JOURNAL OF RESEARCH reports National Burcau of Standards research and development in physics, mathcmatics, and chemistry. Comprehensive scientific papers give complete details of the work, including laboratory data, experimental procedures, and theoretical and mathematical analyses. Illustrated with photographs, drawings, and charts. Includes listings of other NBS papers as issued.

Published in two sections, available separately:

\section{- Physics and Chemistry (Section A)}

Papers of interest primarily to scientists working in these fields. This section covers a broad range of physical and chemical research, with major emphasis on standards of physical measurement, fundamental constants, and properties of matter. Issued six times a year. Annual subscription: Domestic, $\$ 17.00$; Foreign, $\$ 21.25$.

\section{- Mathematical Sciences (Section B)}

Studies and compilations designed mainly for the mathematician and theoretical physicist. Topics in mathematical statistics, theory of experiment design, numerical analysis, theoretical physics and chemistry, logical design and programming of computers and computer systems. Short numerical tables. Issued quarterly. Annual subscription: Domestic, $\$ 9.00$; Foreign, $\$ 11.25$.

\section{TECHNICAL NEWS BULLETTN}

The best single source of information concerning the Bureau's measurement, research, developmental, cooperative, and publication activities, this monthly publication is designed for the industry-oriented individual whose daily work involves intimate contact with science and technology-for engineers, chemists, physicists, research managers, product-development managers, and company executives. Includes listing of all NBS papers as issued. Annual subscription: Domestic, $\$ 6.50$; Foreign, $\$ 8.25$.

\section{NONPERIODICALS}

Applied Mathematics Series. Mathematical tables, manuals, and studies.

Building Science Series. Research results, test methods, and performance criteria of building materials, components, systems, and structures.

Handbooks. Recommended codes of engineering and industrial practice (including safety codes) developed in cooperation with interested industries, professional organizations, and regulatory bodies.

Special Publications. Proceedings of NBS conferences, bibliographies, annual reports, wall charts, pamphlets, etc.

Monographs. Major contributions to the technical literature on various subjects related to the Bureau's scientific and technical activities.

National Standard Reference Data Series. NSRDS provides quantitative data on the physical and chemical properties of materials, compiled from the world's literature and critically evaluated.

Product Standards. Provide requirements for sizes, types, quality, and methods for testing various industrial products. These standards are developed cooperatively with interested Government and industry groups and provide the basis for common understanding of product characteristics for both buyers and sellers. Their use is voluntary.

Technical Notes. This series consists of communications and reports covering both other-agency and NBS-sponsored work) of limited or transitory interest.

Federal Information Processing Standards Publications. This series is the official publication within the Federal Government for information on standards adopted and promulgated under the Public Law 89-306, and Bureau of the Budget Circular A-86 entitled, Standardization of Data Elements and Codes in Data Systems.

Consumer Information Series. Practical information, based on NBS research and experience, covering areas of interest to the consumer. Easily understandable language and illustrations provide useful background knowledge for shopping in today's technological marketplace.

\section{BIBLIOGRAPHIC SUBSCRIPTION SERVICES}

The following current-awareness and literature-survey bibliographies are issued periodically by the Bureau :

Cryogenic Data Center Current Awareness Service (Publications and Reports of Interest in Cryogenics). A literature survey issued weekly. Annual subscription: Domestic, $\$ 20.00$; foreign, $\$ 25.00$.

Liquefied Natural Gas. A literature survey issued quarterly. Annual subscription: $\$ 20.00$.

Superconducting Devices and Materials. A literature survey issued quarterly. Annual subscription: $\$ 20.00$. Send subscription orders and remittances for the preceding bibliographic services to the U.S. Department of Commerce, National Technical Information Service, Springfield, Va. 22151.

Electromagnetic Metrology Current Awareness Service (Abstracts of Selected Articles on Measurement Techniques and Standards of Electromagnetic Quantities from D-C to Millimeter-Wave Frequencies). Issued monthly. Annual subscription: $\$ 100.00$ (Special rates for multi-subscriptions). Send subscription order and remittance to the Electromagnetic Metrology Information Center, Electromagnetics Division, National Bureau of Standards, Boulder, Colo. 80302.

Order NBS publications (except Bibliographic Subscription Services) from: Superintendent of Documents, Government Printing Office, Washington, D.C. 20402. 


\section{U.S. DEPARTMENT OF COMMERCE}

National Bureau of Standards

Washington, D.C. 20234

POSTAGE ANO FEES PAIO

OFFICIAL BUSINESS

U.S. OEPARTMENT OF COMMERCE

215

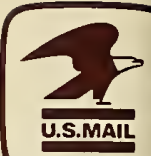

Penalty for Private Use. $\$ 300$ 